\title{
Interventional Radiofrequency Treatment for the Sympathetic Nervous System: A Review Article
}

Nicholas A. Zacharias · Jay Karri · Carol Garcia · Laura K. Lachman •

Alaa Abd-Elsayed

Received: October 23, 2020 / Accepted: November 24, 2020 / Published online: January 12, 2021

(C) The Author(s) 2021

\section{ABSTRACT}

Introduction: Interventional techniques such as radiofrequency (RF) treatment can be used to interrupt pain signals transmitted through the sympathetic nervous system (SNS). RF treatments including the pulsed (PRF) and continuous (CRF) modalities show enhanced control over lesion size and enhanced ability to confirm accurate positioning compared to other interventional methods. PRF also acts to reduce the area of the lesion. In this article, we characterize the currently available evidence supporting the use and efficacy of RF treatments in sympathetically mediated pain (SMP) conditions.

Study Design: A comprehensive literature review.

Methods: A PubMed and Cochrane Library database search was performed for human studies applying RF treatment at sympathetic sites (sphenopalatine ganglion, stellate ganglion, cervical, thoracic, or lumbar sympathetic ganglia, celiac plexus, splanchnic nerves,

N. A. Zacharias · C. Garcia · A. Abd-Elsayed ( $\square)$

Department of Anesthesiology, University of

Wisconsin School of Medicine and Public Health,

Madison, WI, USA

e-mail: alaaawny@hotmail.com

J. Karri · L. K. Lachman

Department of Physical Medicine and

Rehabilitation, Baylor College of Medicine,

Houston, TX, USA superior hypogastric plexus, and ganglion impar) between January 1970 to May 2020. Data were extracted, summarized into tables, and qualitatively analyzed.

Results: PRF and CRF both show promise in relieving SMP conditions, such as complex regional pain syndrome (CRPS), pain in the perineal region, headache and facial pain, and oncologic and non-oncologic abdominal pain, in addition to other types of pain, with minimal complications. Furthermore, in most comparative studies, outcomes using RF treatments exceeded other interventional techniques, such as anesthetic block and chemical neurolysis.

Conclusions: RF treatments can be effective in carefully selected patients who are refractory to conservative management. However, further randomized controlled studies are needed prior to implementing it into common practice.

Keywords: Complex regional pain syndrome (CRPS); Radiofrequency; Sympathectomy; Sympathetic nervous system; Sympathetically mediated pain 


\section{Key Summary Points}

Why carry out this study?

Radiofrequency treatment is an interventional pain management technique that has shown enhanced control over lesion size and an enhanced ability to confirm accurate positioning compared to other interventional methods.

In this review article, we characterize the currently available evidence supporting the use and efficacy of radiofrequency treatments in sympathetically mediated pain conditions.

\section{What was learned from the study?}

Radiofrequency treatment shows promise in alleviating complex regional pain syndrome, pain in the perineal region, headache and facial pain, abdominal pain, and other types of pain with minimal complications.

Patients should be carefully selected for radiofrequency treatment, and further randomized controlled studies are needed prior to implementing it into common practice.

\section{DIGITAL FEATURES}

This article is published with digital features, including a summary slide, to facilitate understanding of the article. To view digital features for this article go to https://doi.org/10.6084/ m9.figshare.13273256.

\section{INTRODUCTION}

The sympathetic nervous system (SNS) has broad-reaching effects and is intricately associated with the central processing of pain through a bidirectional process [1]. Central processing of factors such as pain, immune signals, hormone signals, and others can be projected outwards to the SNS. In the periphery, efferent sympathetic fiber activity upregulates afferent nociceptive fiber pain signals. This exact coupling is not fully understood but may occur through a combination of suggested mechanisms: noradrenaline released by postganglionic sympathetic fibers acts directly on nociceptive fibers to increase pain signals at any point along the nerve and/or SNS activity contributes to increased pain perception indirectly via interaction with other processes (e.g., blood flow and immune function) [1]. Sympathetically maintained pain (SMP) can occur in various pain syndromes such as complex regional pain syndrome (CRPS) and cluster headache, which have a prevalence of 25/100,000 [2] and 0.5-1.0/1000 [3], respectively. Pain due to abdominal cancer is another example. Ninety percent of patients with cancer of any type will experience pain due to their disease [4], and patients with pancreatic cancer, in particular, experience the highest rates of pain [5]. SMP also occurs in many other pain syndromes. Pain syndromes with this feature can be substantially debilitating by affecting work, relationships, and psychological wellbeing in addition to the physical manifestations $[2,3,6]$. The SNS appears to propagate signals from many different origins of pain including neuronal, visceral, vascular, and musculoskeletal entities [7, 8]. SNS-driven pain signaling can be dampened via neural blockade of key sympathetic nerves or ganglia. Pain relieved by SNS blockage is said to be SMP [2, 9], whereas pain not relieved by SNS blockage is considered sympathetically independent pain (SIP) $[2,9]$. Typically, temporary nerve blocks are used with diagnostic intent to distinguish between these clinical features before neurolytic measures are pursued [10-12]. Sympathetic targets in clinical practice primarily include sphenopalatine ganglion, stellate ganglion, thoracic or lumbar ganglia, celiac plexus, splanchnic nerves, superior hypogastric plexus, and ganglion impar $[7,8]$. Though some of these structures are not composed solely of sympathetic fibers, it is believed that the lasting relief occurs from blocking transmission of the SNS signals at these sites $[7,8]$. 
Interventional procedures in pain management are typically utilized after failure of conservative measures and pharmacotherapies $[2,3,5,13-15]$. Nerve blocks are a useful tool for diagnosis and treatment, but effects may be temporary [10-12]. Neurolytic procedures may extend these effects. While these procedures carry more inherent risk, potential benefits can far exceed their risk in carefully selected patients with refractory pain phenomena [2, 3, 5, 13-15]. Neurolytic procedures (e.g., chemical neurolysis, cryotherapy, and radiofrequency $[\mathrm{RF}]$ treatment) are all valuable and evidenced interventional strategies $[8,16]$. Spinal cord stimulation has also shown promise as an alternative strategy, but further study is required to optimize stimulation patterns and parameters in SMP conditions [17]. RF approaches have been applied to an increasing number of SMP conditions because of their ability to create controlled lesions in discrete anatomic locations, with a low propensity for complications relative to other neurolytic measures [8]. Given their promise for treating SMP, we aim to characterize the currently available evidence supporting the use and efficacy of RF treatments in SMP conditions.

\section{RF Technique}

RF treatment exists in two forms: continuous RF treatment (CRF) and pulsed RF treatment (PRF). CRF functions by sending an alternating current through an electrode tip, which generates destructive heat through ionic oscillations created in surrounding tissue [18]. Generated temperature is controlled by adjusting the current and voltage passing through the device in the neuro-destructive treatment range of $45-90{ }^{\circ} \mathrm{C}$ [18]. The size of the lesion is controlled by the treatment temperature, duration of treatment, and gauge $(\mathrm{G})$ of the electrode [18]. Maximum size is achieved at about $90 \mathrm{~s}$. Accurate positioning of the electrode prior to treatment can also be confirmed by using low voltage at specific frequencies to produce a nondestructive current [18]. This can yield a test current for sensory stimulation $(50 \mathrm{~Hz}$ frequency) and for motor stimulation $(2 \mathrm{~Hz}$ frequency), which helps to mitigate off-target effects in the surrounding neural structures [18]. Because CRF operates through destructive means, it is generally reserved for non-neuropathic pain, as the target fibers should not contain essential sensory and motor fibers $[16,18]$.

PRF functions by utilizing short bursts $(20 \mathrm{~ms})$ of current two times per second. This allows the use of higher voltages while limiting temperature in the target tissue to under the neurolytic level of $45^{\circ} \mathrm{C}[18,19]$. Motor and sensory stimulation can also be carried out in PRF to ensure accurate positioning [18]. The therapeutic effect may stem from electric field generation and resultant modulation of nerve signaling, though the exact mechanism is not fully understood $[18,19]$. Data also show that it may not be fully nondestructive [18]. The application of PRF treatment has been debated, but it is a particularly useful strategy for neuropathic pain states where nerve damage is already a primary feature $[16,18]$. Overall, RF treatment is a valuable asset for selective patient populations due to its mode of action. Advantages of its methodology include control over lesion size, multiple modalities, and the ability to confirm accurate positioning.

\section{METHODS}

An online literature search was performed via the PubMed and Cochrane Library databases on the use of RF treatment in the SNS. Review of references was also performed to collect additional studies. The search terms used were radiofrequency ablation (RFA), radiofrequency, thermal neurolysis, sympathetic neurolysis, and sympathectomy in combination with descriptors of pain including complex regional pain syndrome (CRPS) and sympathetic mediated pain as well as sympathetic, ganglia, plexus, splanchnic, and pain. The search was limited to the English language and human studies ranging from January 1970 to May 2020. Furthermore, the studies included in this review were limited to those describing RF treatments of the following sympathetic targets applied in clinical practice $[7,8]$ : sphenopalatine ganglion, stellate 
ganglion, cervical, thoracic, or lumbar sympathetic ganglia, celiac plexus, splanchnic nerves, superior hypogastric plexus, and ganglion impar. Of note, it is possible that sympathetic activity may play a role outside these SNS sites, such as in the dorsal root ganglia as well as sinuvertebral and basivertebral nerves, but the pathophysiology is not well understood and it was therefore not included in this study [9, 20-22].

Due to the vast diversity of study types, comparison groups, pain phenomena, RFAspecific variables, and reported outcomes, it was impossible to homogenize data sufficient for further analytics. Additionally, all data presented in this review were from previously published studies, and the review does not contain any studies performed by the authors of this article.

\section{RESULTS}

Figure 1 shows a flow diagram of the literature search and study selection adapted from the Preferred Reporting Items for Systematic Reviews and Meta-Analyses (PRISMA) [27]. Fifty-seven original studies (7 randomized controlled trials, 21 retrospective analyses, 3 prospective analyses, 1 center experience, 7 case series, and 18 case reports) were included in this review. These studies (excluding case series and reports) are summarized in Tables 1, 2, 3, 4, and 5. Studies involving RF treatment of the SNS primarily focused on its efficacy in CRPS (Table 1) [28-36], pain in the perineal region (Table 2) [37-48], headache and facial pain (Table 3) [49-63], and oncologic and non-oncologic abdominal pain (Table 4) [64-75] in addition to other types of pain (Table 5) [76-85].

\section{DISCUSSION}

\section{Relevant Anatomy}

Applying RF treatments clinically, as with any neurolytic procedure, requires a detailed understanding of the target and surrounding anatomy to ensure both efficacy and avoidance of serious complications [8, 10-12]. The SNS contains preganglionic inputs originating in the lateral horn of the spinal cord from the T1-L2 vertebral levels. These inputs synapse with postganglionic cell bodies that are either paravertebral (sympathetic chain alongside vertebral column) or prevertebral (along the abdominal aorta and ventral branches). Postganglionic fibers are then spread diffusely across the body to target sites.

The sphenopalatine ganglion receives sympathetic inputs from the postganglionic fibers from the cervical level [11] and contains inputs from parasympathetic, sensory, and secretomotor fibers [7]. It is located deep within the pterygoid fossa at the opening of the pterygoid canal posterior to the maxillary sinus [7]. It is thought that blocking sympathetic activity at this site plays a major role in therapeutic practice [7], but it is important to consider the diversity of fibers in this ganglion that may also be contributory.

Paravertebral ganglia span the length of the vertebral column and traverse on the lateral aspects until it fuses at the ganglion impar. Prevertebral ganglia form when preganglionic fibers pass through paravertebral ganglia without synapsing. There are three cervical ganglia. The inferiormost is the inferior cervical ganglion or the stellate ganglion. The stellate ganglion is typically formed by a fusion of ganglia at the $\mathrm{C} 7$ and T1 levels $[12,23]$, but may involve fusion of ganglia as far as T4 [23]. It is located anterior to the transverse processes, anteromedial to the vertebral artery, and medial to the common carotid artery and jugular vein [12].

With the exception of T1, thoracic ganglia lie at the posterolateral aspect of the vertebral column with the pleural space anterolateral [24]. Preganglionic fibers may synapse in the sympathetic chain in order for postganglionic fibers to travel with spinal nerves or to the cardiac plexus [23]. Alternatively, in the region of T5-T12, preganglionic fibers may pass through the paravertebral ganglia and give rise to the three thoracic splanchnic nerves. The greater splanchnic nerve originates from T5 or T6 to T9 or T10 levels, the lesser splanchnic nerve originates from the $\mathrm{T} 9$ and $\mathrm{T} 10$ or $\mathrm{T} 10$ and $\mathrm{T} 11$ 

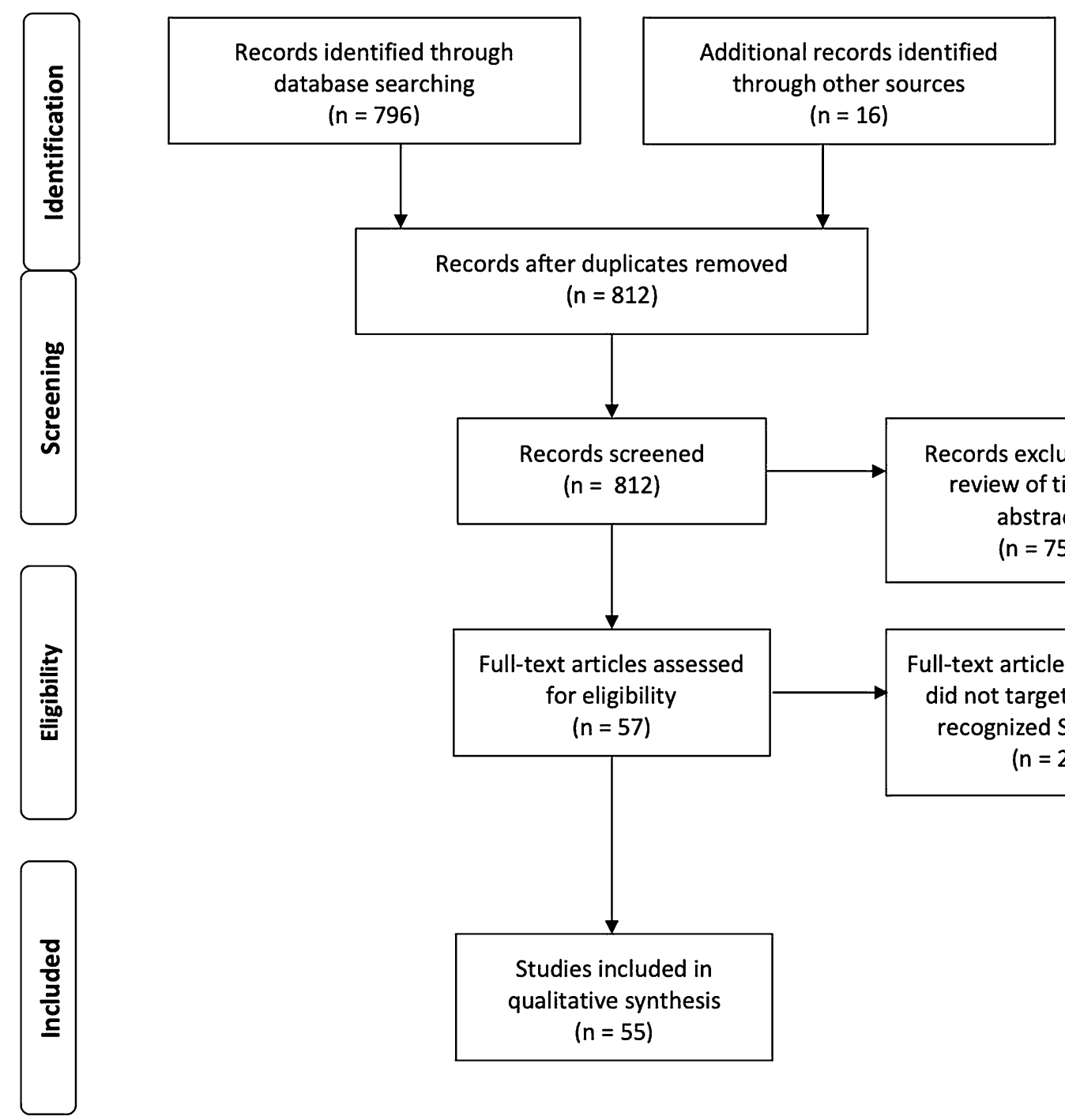
$(n=812)$

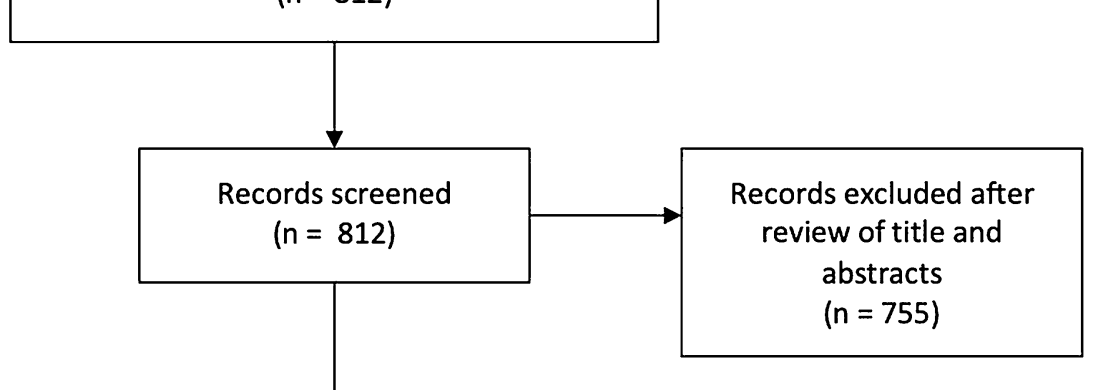

Fig. 1 Flow diagram adapted from PRISMA [27]

levels, and the least splanchnic nerve originates from the T11 and T12 levels [23, 25]. The thoracic splanchnic nerves then synapse within the celiac plexus, which helps transmit nociceptive signals from abdominal viscera $[23,25]$. The celiac plexus is a prevertebral ganglia that encircles the celiac and superior mesenteric arteries at the branch point from the abdominal aorta $[23,25]$. This area is in the retroperitoneal space and is surrounded by the abdominal aorta immediately posterior, the inferior vena cava to the right, and the pancreas immediately anterior [25].
Paravertebral lumbar sympathetic ganglia can be variable in number and location [23]. However, generally, these ganglia are located anterolaterally to the lumbar vertebrae with the peritoneal cavity anterolateral, abdominal aorta and inferior vena cava anterior, and somatic nerves in close proximity [10]. Preganglionic fibers in the lumbar region may synapse in the sympathetic chain in order for postganglionic fibers to travel with spinal nerves. Alternatively, preganglionic fibers may travel to lumbar splanchnic nerves destined for the abdominal aortic, inferior mesenteric, and hypogastric plexuses [23]. 


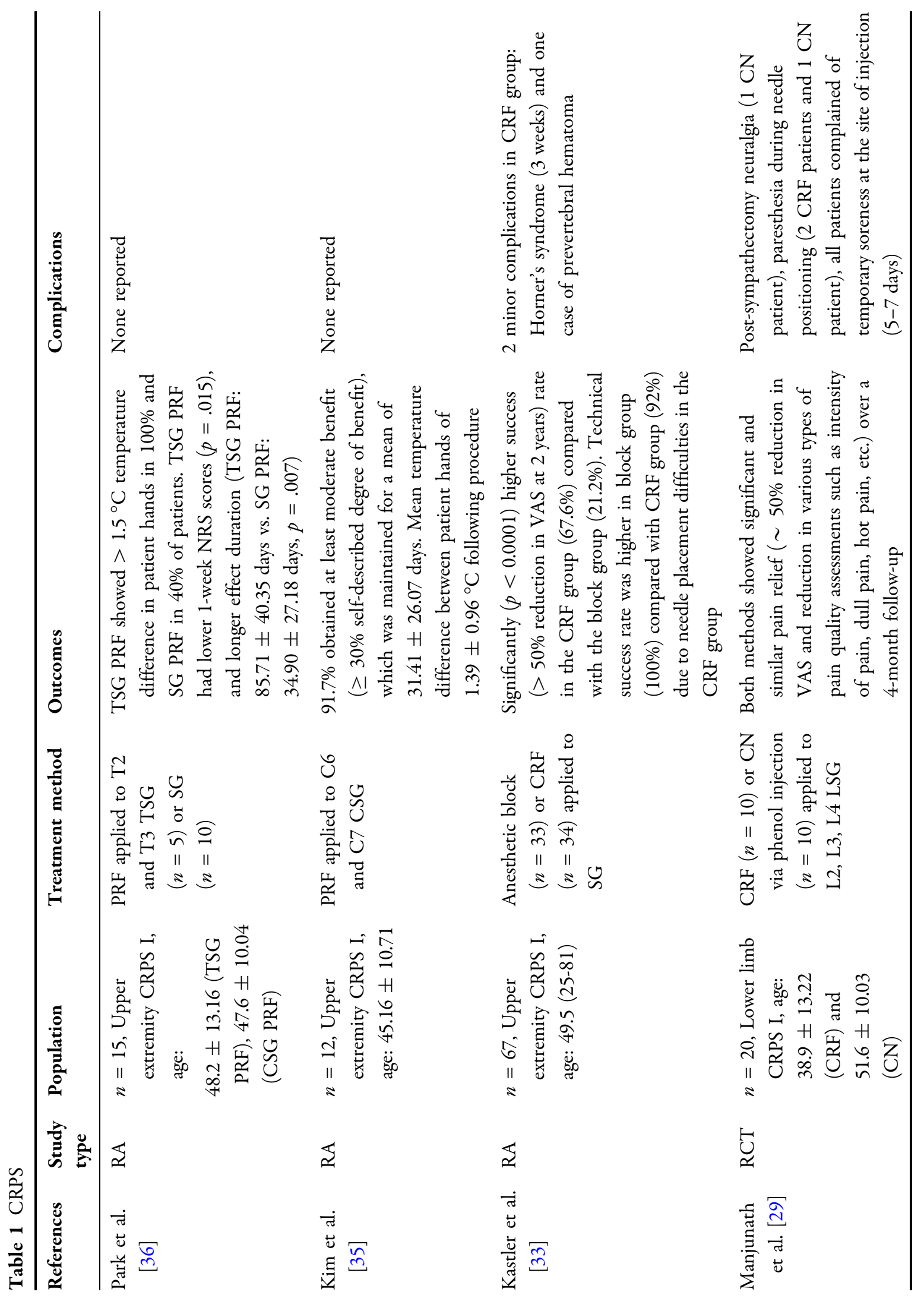




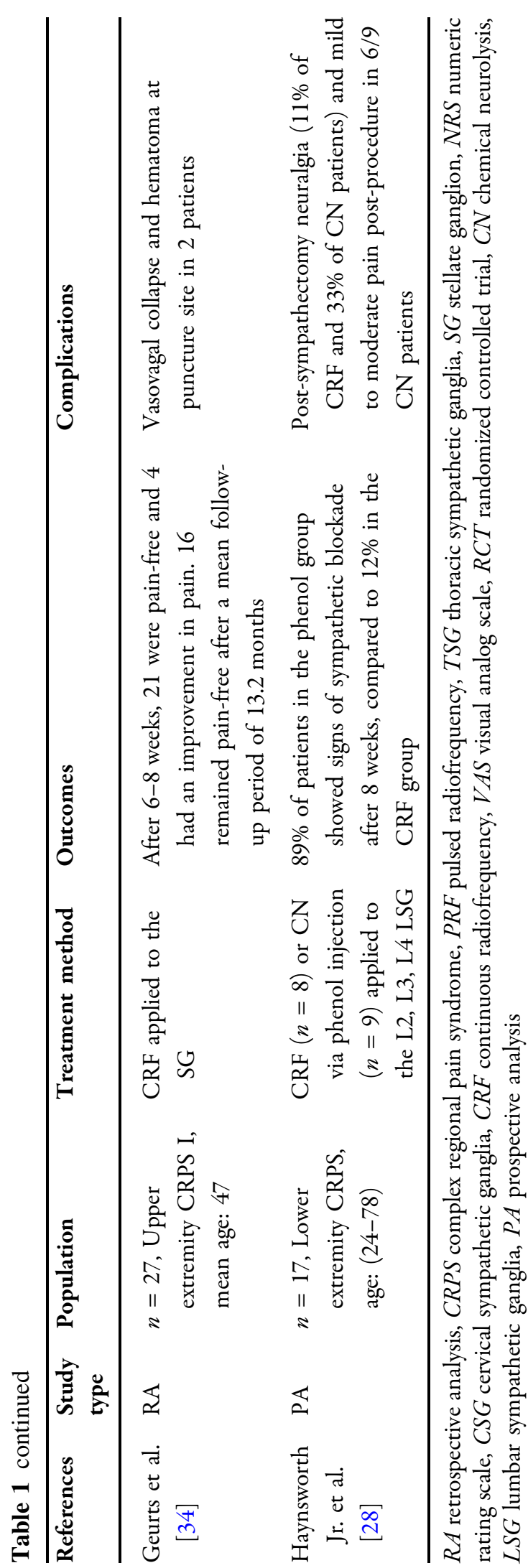

The ganglion impar is formed by the fusion of the right and left sympathetic chains receiving inputs from lumbar and sacral sympathetic and parasympathetic fibers $[23,26]$. It is located anterior to the sacrococcygeal junction and posterior to the rectum and helps provide innervation to pelvic viscera and genitalia [26].

\section{Chronic SMP Conditions}

\section{CRPS}

CRPS is a condition that is principally characterized by persistent regional pain (either spontaneous or evoked) often accompanied by allodynia and hyperalgesia. It may also present with myriad other symptoms including autonomic disturbances (edema, change in skin temperature, sweating, or change in skin color), motor impairments, or trophic changes (alterations to hair, skin, or nails). This may occur following a lesion, trauma, or other inciting event. The pain also does not coincide with the degree or timing of the event. There are two types of CRPS. CRPS type 1 (reflex sympathetic dystrophy) occurs in the absence of nerve injury, and CRPS type 2 (causalgia) involves peripheral nerve injury [2, 17]. Multidisciplinary collaboration including pain management, physical/occupational therapy, and psychological therapy is essential in the treatment of CRPS [2, 17]. Pain management is especially critical to make physiotherapy tolerable $[2,17]$. First-line treatment involves a combination of carefully considered pharmacologic agents including nonsteroidal anti-inflammatory drugs (NSAIDs), anticonvulsants (gabapentin, pregabalin, and carbamazepine), steroids, opioids, and others $[2,17]$. Second-line therapies involve interventional procedures $[2,17]$. Sympathetic ganglion blocks can be effective diagnostic and treatment tools [2, 17]. Additional interventional procedures, such as spinal cord stimulation (SCS), intrathecal drug delivery, sympatholytic procedures, and PRF, can all be valuable if pain remains refractory $[2,17]$.

Studies investigating the effectiveness of RF treatment in CRPS have targeted lumbar sympathetic ganglia at the L2, L3, and L4 vertebral 


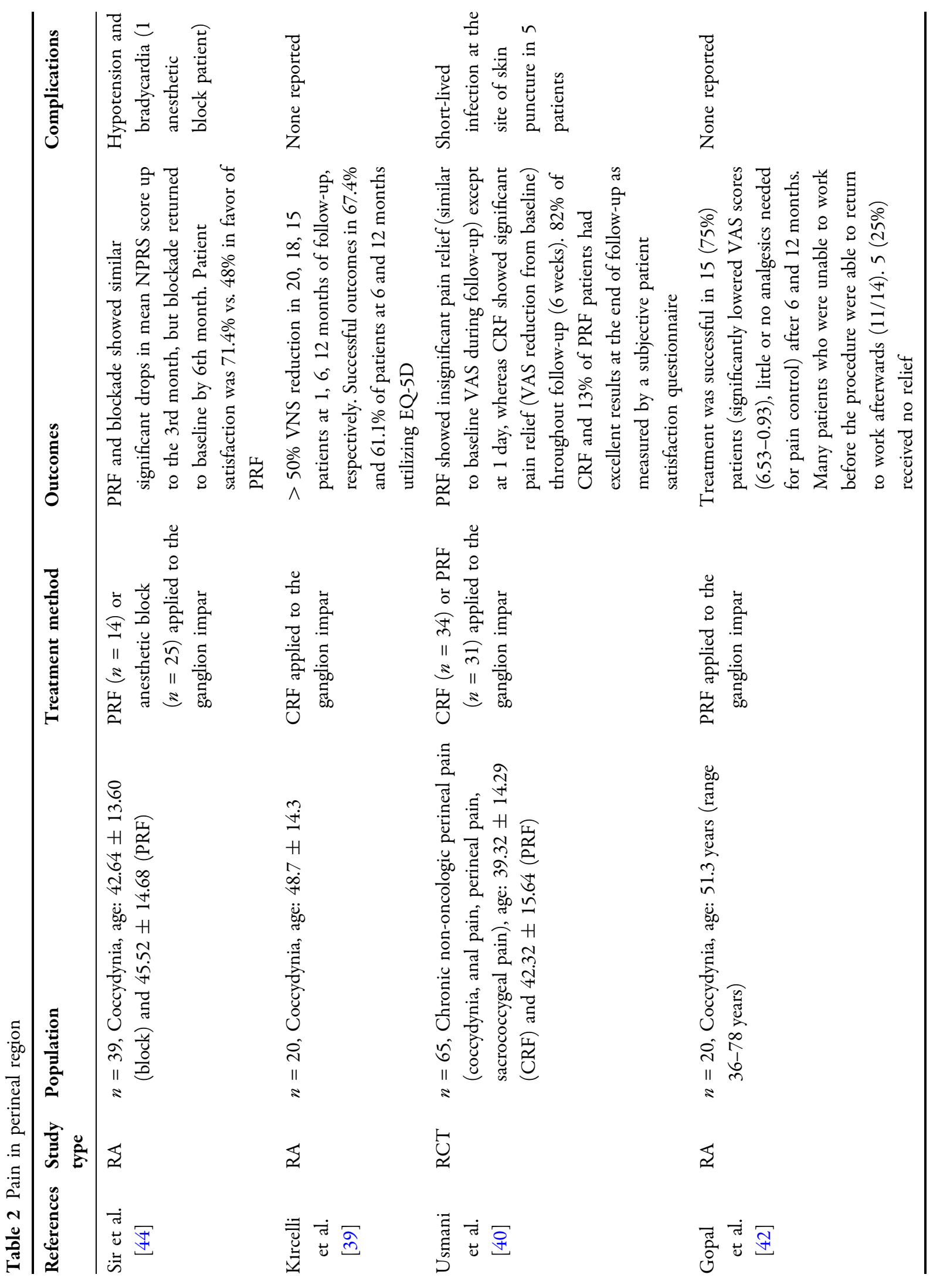




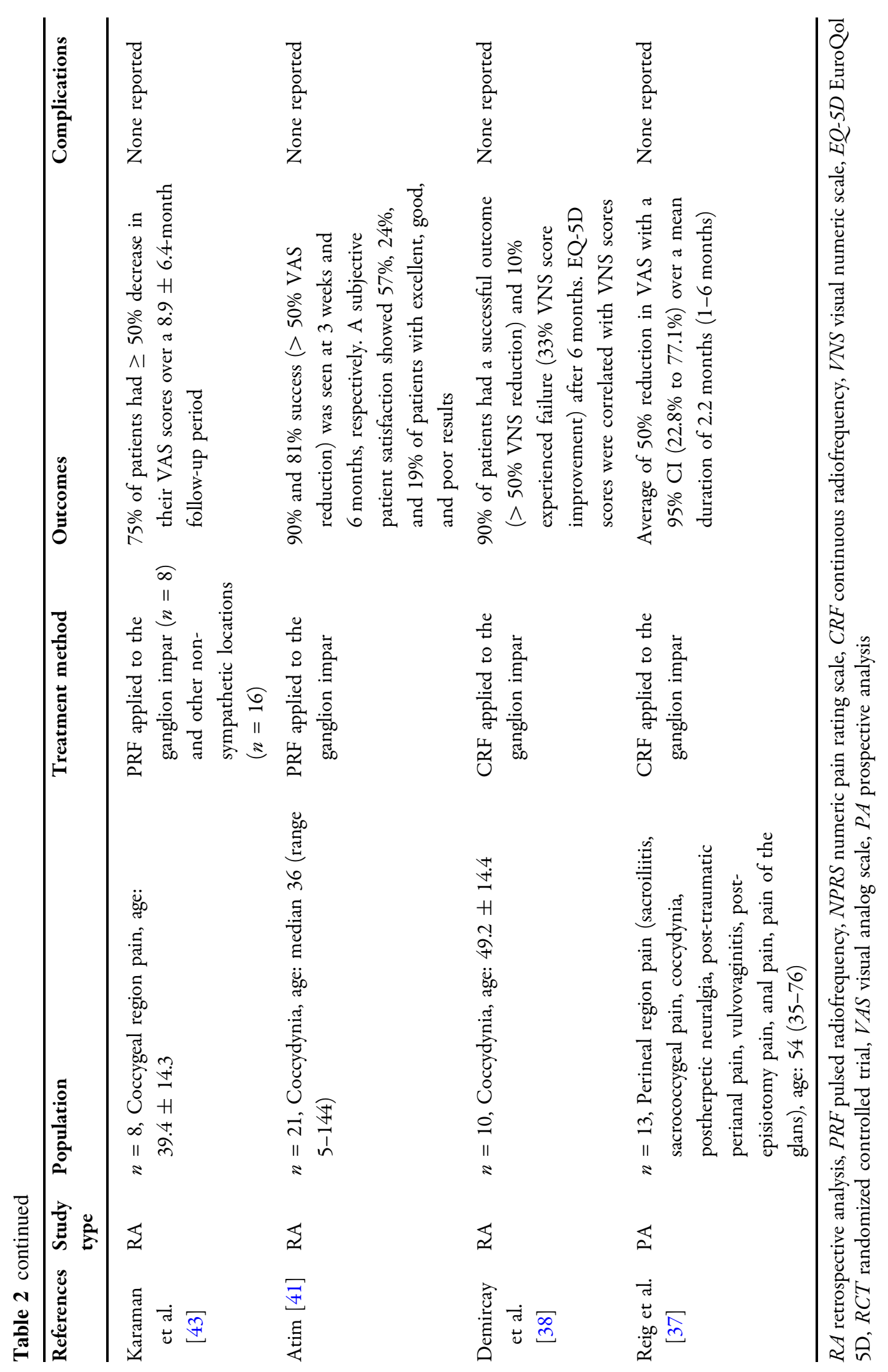




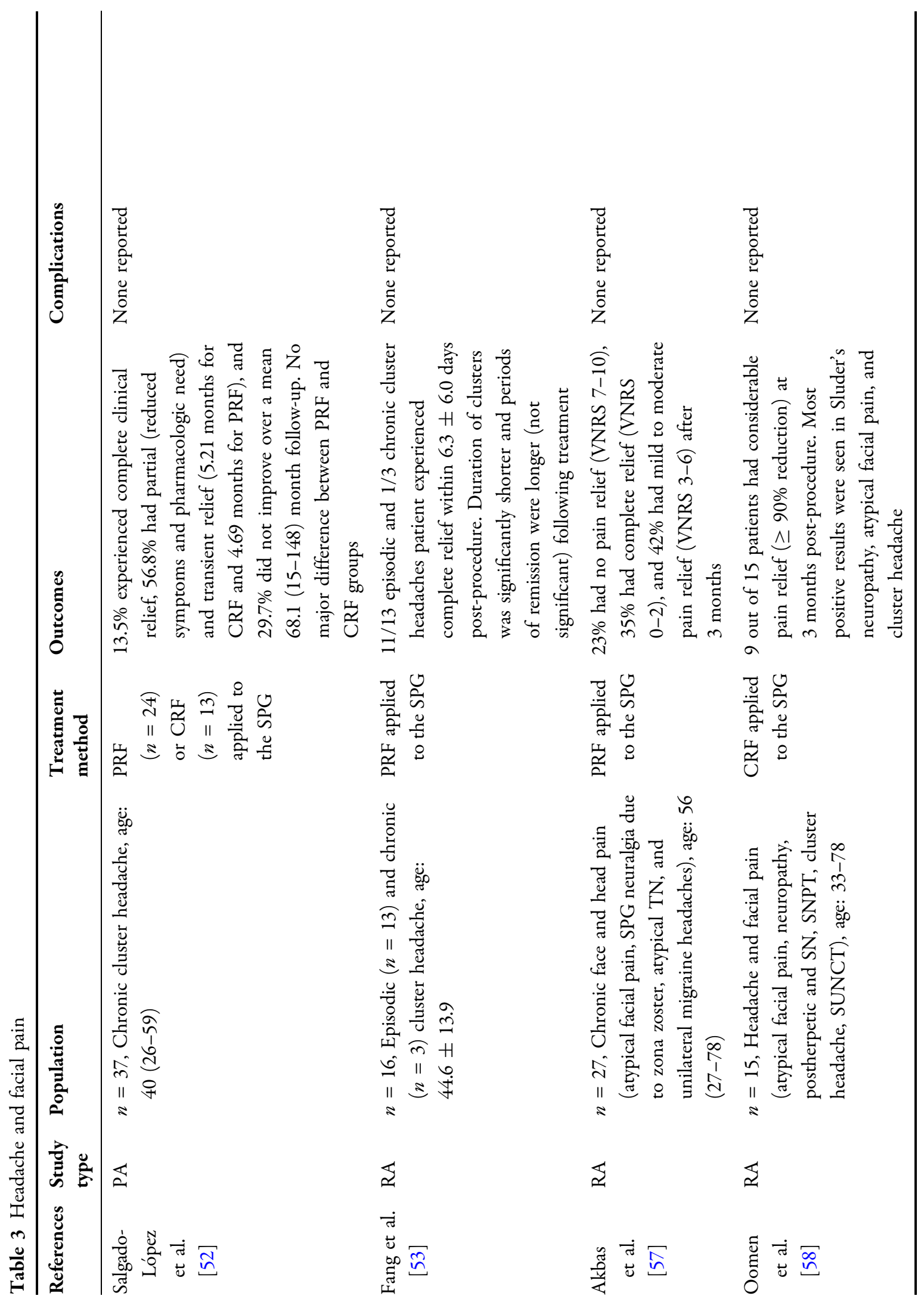




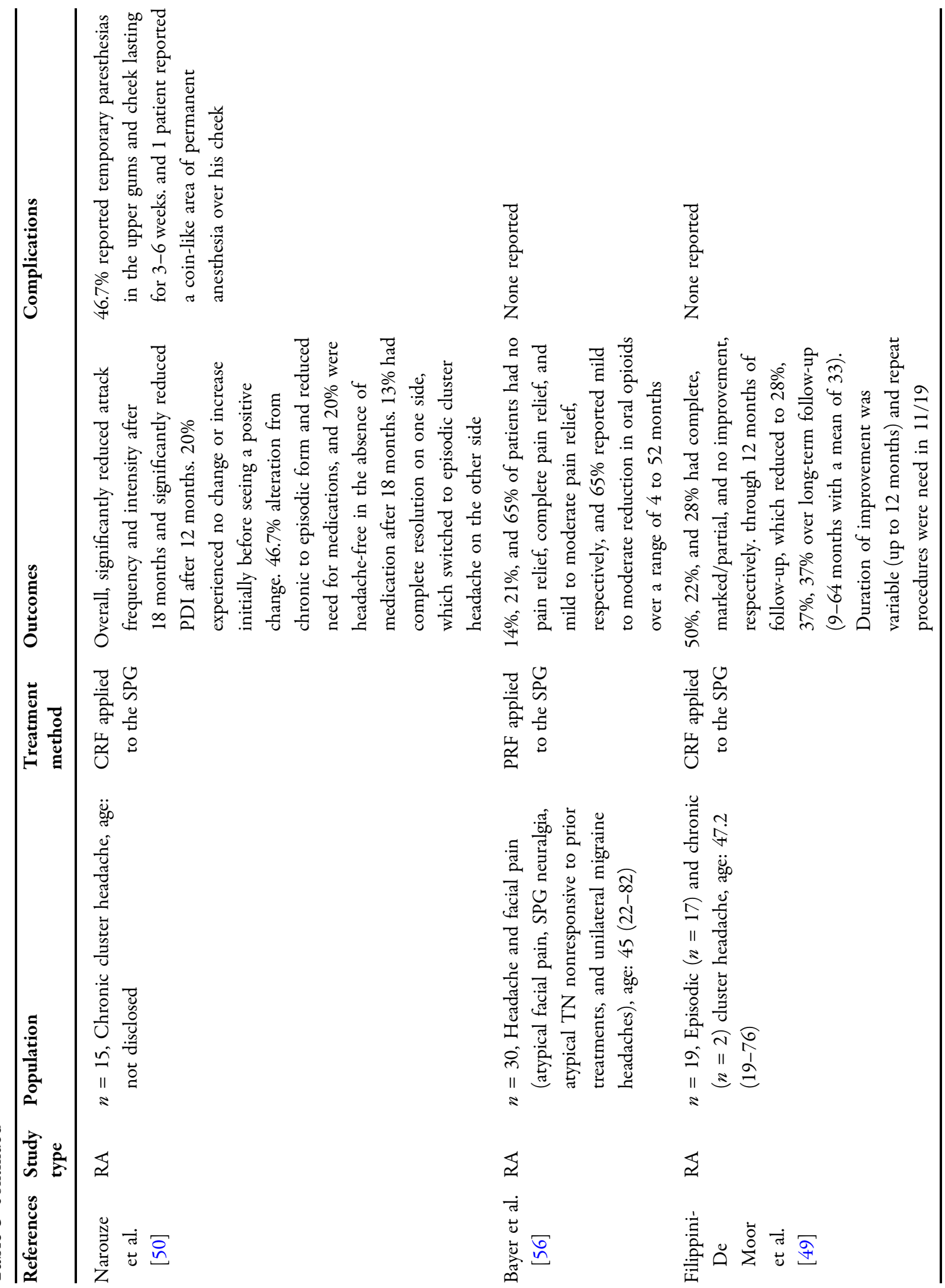




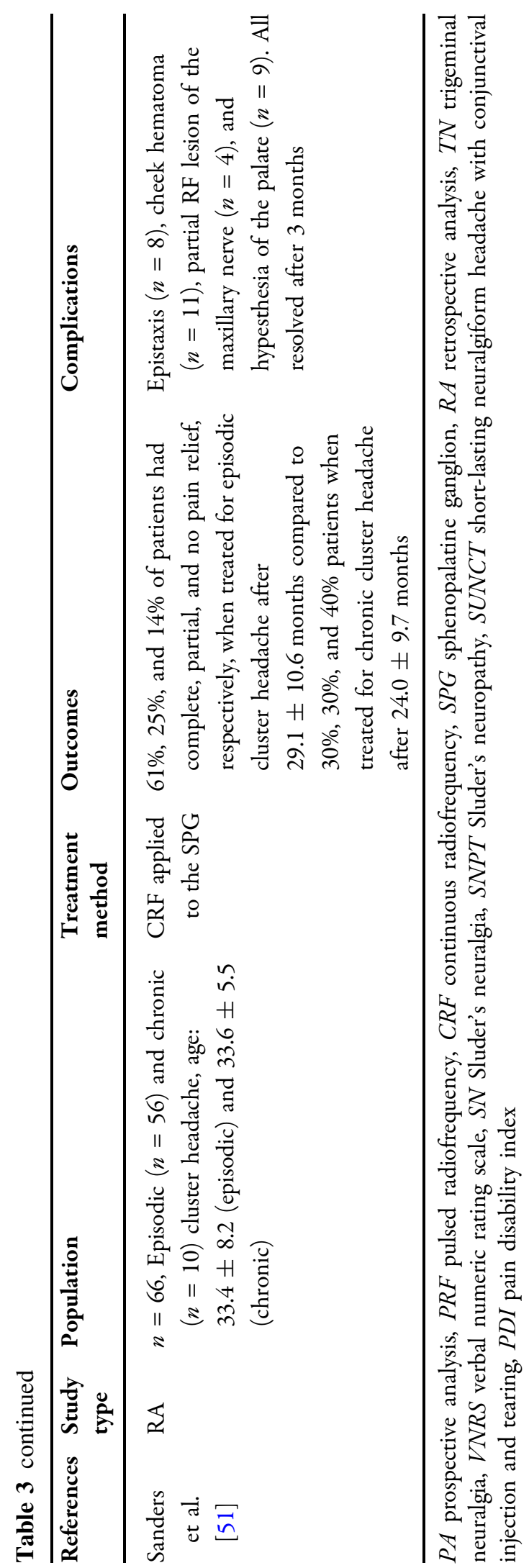

levels for lower extremity CRPS [28-31] and either thoracic sympathetic ganglia at the T2 and $\mathrm{T} 3$ vertebral levels or the stellate ganglion for upper extremity CRPS [32-36]. Earlier studies included in this review investigated the use of CRF in CRPS, which transitioned to PRF more recently. Additionally, most focused primarily on CRPS I. However, Rana et al. successfully applied PRF to the stellate ganglia in in a patient with CRPS II [32].

The evidence for CRF vs. chemical neurolysis for the treatment of lower extremity CRPS is unclear. While Haynsworth et al. reported significant superiority of sympathetic blockade with chemical neurolysis 8 weeks post-procedure (89\% vs. $12 \%$ with CRF) [28], Manjunath et al. reported similar successes in pain reduction with both options across 4 weeks postprocedure [29]. Little evidence for application of PRF in lower extremity CRPS exists. One case report showed a decrease in level of pain, edema, and color change in the skin at 4 months [30]. One case series involving repeated procedures in three patients showed $>$ $50 \%$ reduction in the numeric rating scale for pain (NRS) in $91.7 \%, 83.3 \%$, and $21 \%$ of procedures at 3,6 , and 12 months, respectively [31].

Studies using CRF for upper extremity CRPS showed promise for longer-term pain relief compared to PRF, where effects appeared temporary. Kastler et al. reported a higher rate of $>50 \%$ reduction in visual analog scale for pain (VAS) at 2 years in patients receiving CRF at both the $\mathrm{C} 7$ and $\mathrm{T} 1$ levels compared to anesthetic block (67.6\% vs. $21.2 \%)$ [33]. Of note, the C7 level of the stellate ganglion could not be accessed in 4/34 patients, which may indicate poor suitability of this procedure in a small portion of patients [33]. In agreement, Geurts et al. reported that $78 \%$ of patients receiving $\mathrm{CRF}$ at the $\mathrm{C} 7$ level were pain-free at 6-8 weeks post-procedure, with 59\% remaining pain-free at a mean of 13.2 months post-procedure [34]. Studies applying PRF to both the C6 and C7 levels [35] and the C7 level alone [36] reported similar temporary analgesic effects, with lowered NRS scores at $31.41 \pm 26.07$ days [35] and $34.90 \pm 27.18$ days [36], respectively. However, the length of this analgesic effect 


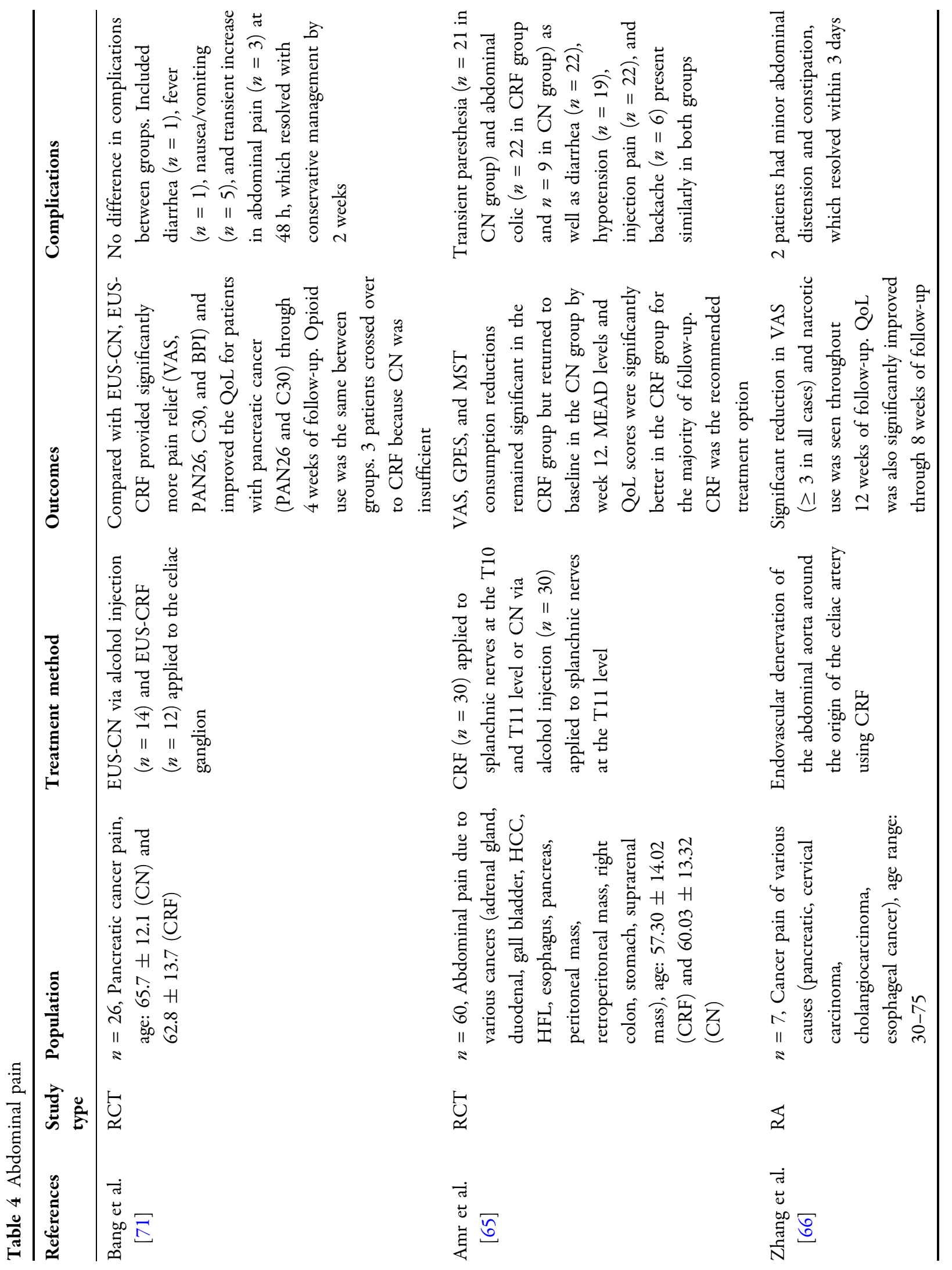




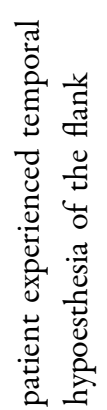

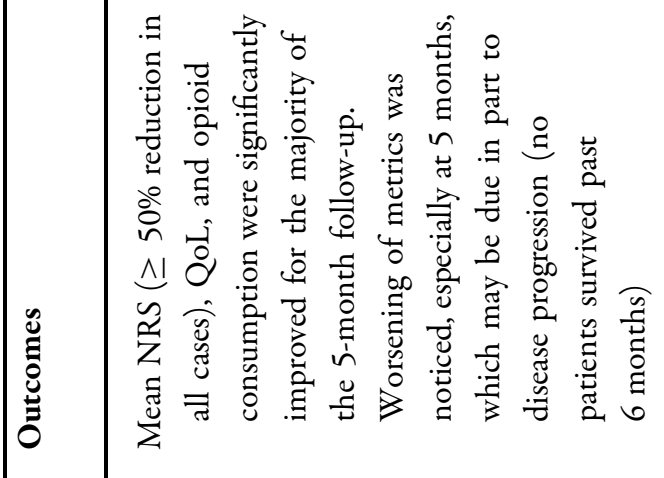

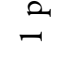

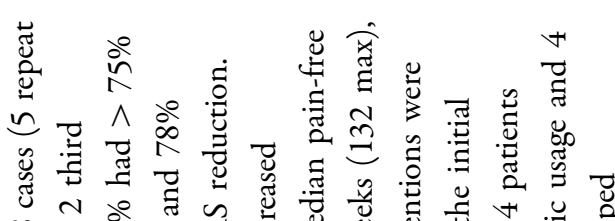

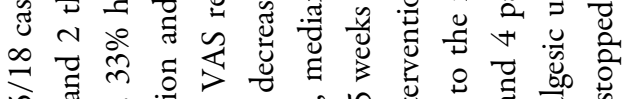

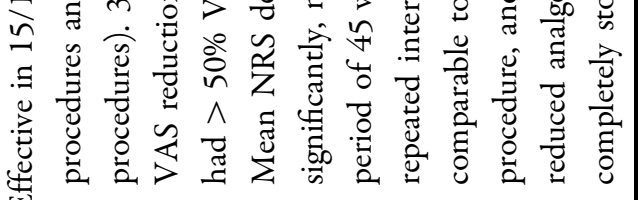
$\stackrel{\text { I }}{F}$
氜

F

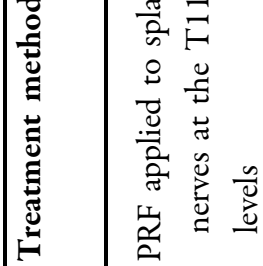

के Е

온

号

空
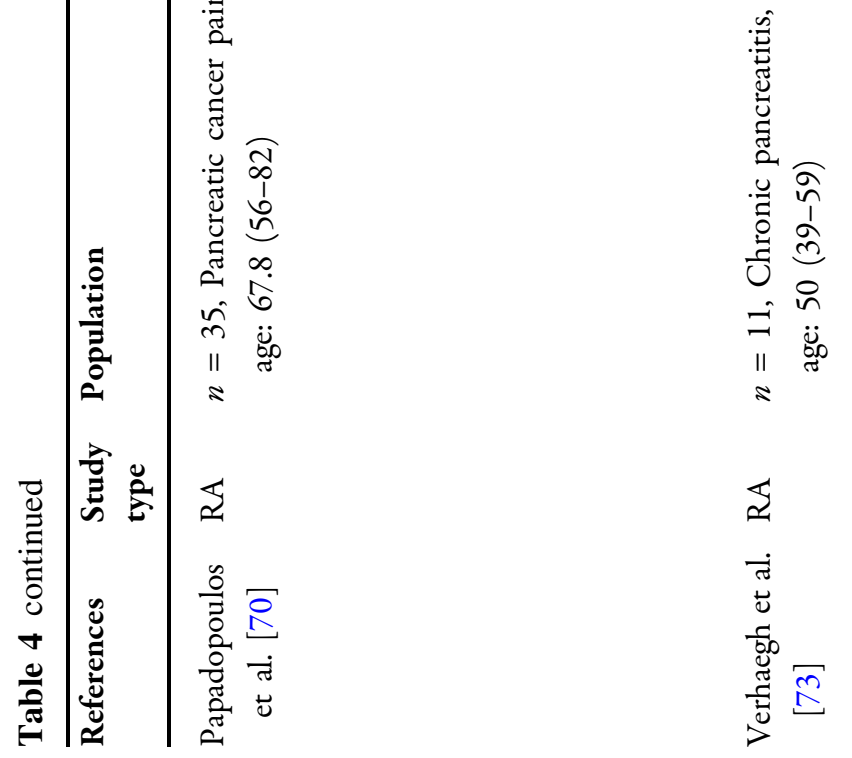


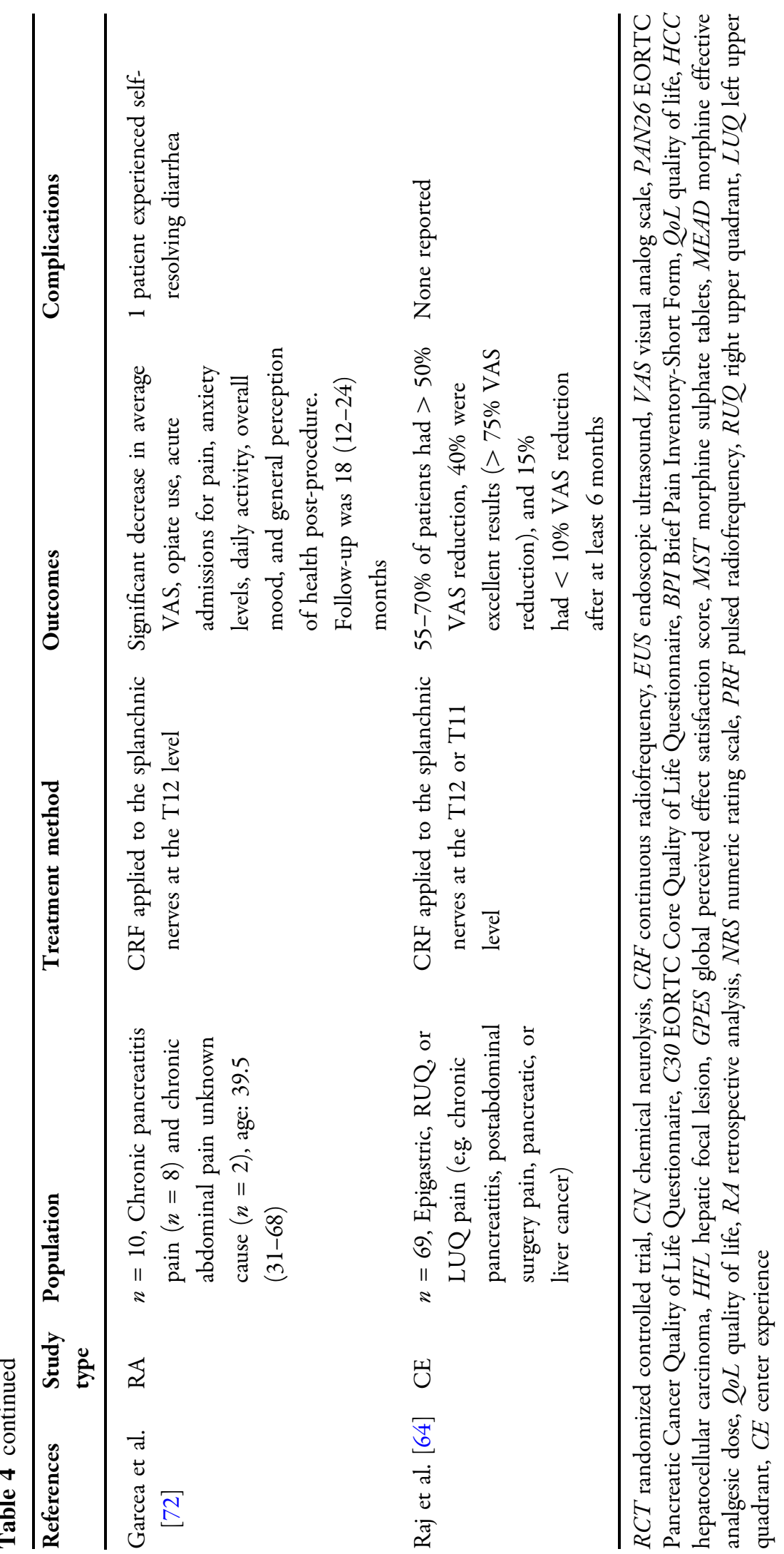




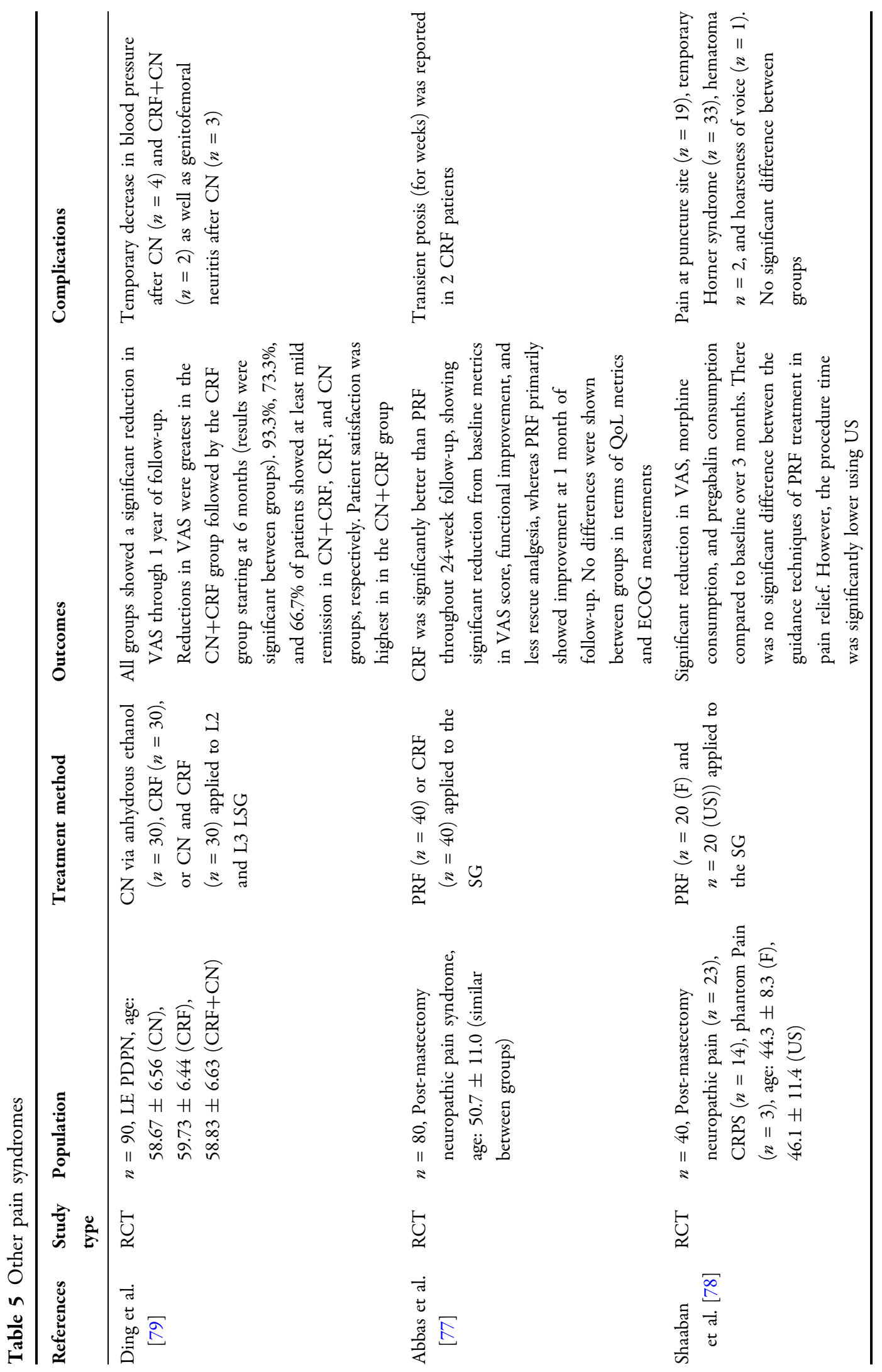




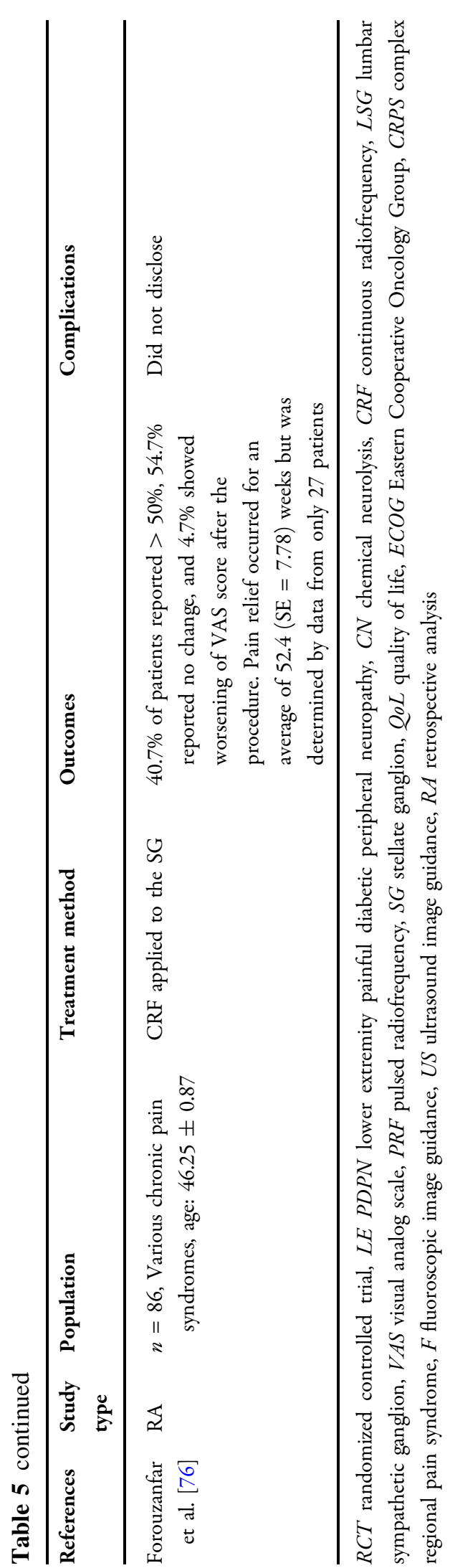

nearly doubled (85.71 \pm 40.35 days) when applied to the T2 and T3 levels [36]. Furthermore, evidence of sympathetic blockade was seen in $100 \%$ of procedures performed at the $\mathrm{T} 2$ and T3 levels vs. $40 \%$ at the C7 level [36]. Overall, in patients with CRPS, chemical neurolysis had similar or greater success compared to CRF, and CRF provided longer relief than anesthetic block. Data on the use of PRF in CRPS were limited and effects seemed to be temporary.

Pain in the Perineal Region Multiple pain syndromes exist in the perineal region, including coccydynia, vulvodynia, perineal pain, rectal pain, and others [6]. Of these pain syndromes, coccydynia has been the most extensively studied as a candidate for RF treatment. Coccydynia refers to pain that is well localized to the tailbone or coccyx just above the anus, generally in the absence of low back pain or radiation. It can result from trauma (falls, childbirth, recent surgery, etc.) or repetitive microtraumas from body positioning, or may develop idiopathically. First-line treatment involves modifying the sitting position, pain relief medications such as NSAIDs, and/or physiotherapy involving intrarectal manipulation of the coccyx $[14,15]$. Interventional procedures such as local anesthetic or corticosteroid injections, RF treatment of the ganglion impar, stimulation therapy, and coccygectomy have all been investigated as possible modes of treatment as alternative solutions for refractory pain $[14,15]$. Other pain syndromes in the perineal region follow a similar regimen of medical management, with common pain medications, local therapies, physical therapy, psychological support, and interventional techniques for refractory cases [6].

CRF has shown capacity for long-term success when applied to the ganglion impar for pain syndromes in the perineal region, but studies report mixed results when using PRF. Reig et al. reported a mean VAS reduction of approximately $50 \%$ in patients with various types of perineal region pain (sacroiliitis, sacrococcygeal pain, coccydynia, etc.) receiving $\mathrm{CRF}$ at a mean of 2.2 months post-procedure [37]. Focusing specifically on coccydynia, 
Demircay et al. and Kircelli et al. reported nearly identical results: $90 \%$ of patients receiving CRF experienced a $>50 \%$ pain reduction as measured by visual numeric scale (VNS) and VAS scores, respectively, at 6 months post-procedure, along with similarly correlated EuroQol 5D (EQ-5D) index scores in both studies $[38,39]$. Additionally, in the study performed by Kurcelli et al., VAS reduction was maintained in $75 \%$ of patients at 12 months [39]. Usmani et al. compared PRF to CRF in a population of patients primarily with coccydynia $(85.4 \%$ in the CRF group and $80.6 \%$ in the PRF group), but other types of perineal region pain as well (coccydynia, anal pain, perineal pain, and sacrococcygeal pain) [40]. The mean reduction in VAS score compared to baseline was significant through 6 weeks of follow-up post-procedure in the CRF group, but not the PRF group [40]. Similarly, $12.9 \%$ of PRF patients compared to $82.3 \%$ of CRF patients reported excellent results on a subjective patient questionnaire [40].

Results for the PRF group in the study performed by Usmani et al. were contradicted by four other studies also reporting on the use of PRF applied to the ganglion impar, but these studies focused specifically on coccydynia [41-44]. Atim et al. reported $>50 \%$ VAS reduction at 3 weeks and 6 months post-procedure in $90 \%$ and $81 \%$ of patients, respectively, with $57 \%$ and $24 \%$ of patients experiencing excellent and good results, respectively, as measured by a subjective questionnaire [41]. Similarly, Gopal et al. at 6 and 12 months post-procedure and Karaman et al. at a mean of $8.9 \pm 6.4$ months post-procedure reported $>50 \%$ reduction in VAS scores in $75 \%$ of patients $[42,43]$. Lastly, Sir et al. reported a greater length of effect using PRF compared to anesthetic block [44]. Mean numeric pain rating scale (NPRS) scores were similarly reduced compared to baseline in both groups at 3 months post-procedure, but only in the PRF group at 6 months post-procedure. Patient satisfaction also favored PRF on the Likert scale (LS) $(71.4 \%$ vs. $48 \%)$ [44].

Though the majority of data on the use of RF to alleviate perineal region pain has been reported in the context of coccydynia, broader application is possible based on limited data.
Reig et al. and Usmani et al. report on the use in various other types of perineal region pain $[37,40]$. Similarly, CRF applied to the ganglion impar has shown success in case reports of patients with pain due to colon cancer malignancy [45] and constant anal pain [46]. Additionally, PRF was successfully applied to the superior hypogastric plexus through 2.5 years of follow-up to treat pain in a patient with interstitial cystitis [47]. Taken together, CRF and PRF of the ganglion impar both show capacity for long-term relief in pain syndromes in the perineal region. Specifically, PRF showed longer relief than anesthetic block, but the success of PRF was mixed among studies.

Headache and Facial Pain The sphenopalatine ganglion propagates pain in many headache and facial pain syndromes, such as cluster headache, migraines, hemicrania continua, and atypical facial pain $[3,7,86]$. Cluster headache has been the most extensively studied as a candidate for RF treatment targeting the sphenopalatine ganglion. Cluster headache is part of a group of syndromes called trigeminal autonomic cephalgias, where pain is located along the first division of the trigeminal nerve. It is regarded as one of the most severe primary headache syndromes and one of the worst pain syndromes [13]. Cluster headaches are characterized by unilateral pain in the orbital, supraorbital, or temporal region in addition to facial autonomic symptoms (ptosis, miosis, lacrimation, etc.) and systemic autonomic features (bradycardia, hypertension, vertigo, etc.). Cluster headaches typically follow a circadian periodicity. Most occur episodically with periods of attacks and remission throughout a given year, but some may occur chronically [3, 13]. Treatment of cluster headaches is multifaceted, requiring patient education, acute abortive therapy of an attack (i.e. oxygen or a triptan), and prophylactic therapy. Initial approaches to prophylactic therapy typically involve pharmacologic intervention such as verapamil, lithium carbonate, topiramate, glucocorticoids adjunctly, and others [3, 13]. However, alternative interventional procedures such as neurostimulation, nerve blocks, deep brain stimulation, and RF treatment are essential 
considerations in patients with refractory disease $[3,13]$. Treatment regimens for other headache and facial pain syndromes differ because of the unique episodic nature of cluster headache. However, treatments generally begin with medical management before progressing to interventional and surgical measures $[57,86]$.

The sphenopalatine ganglion was the only sympathetic target used to treat headache and facial pain in the studies included in this review. Other targets such as the trigeminal ganglion or various nerves in the head and face may have application in treating the same or similar conditions, but were not considered sympathetic targets and were excluded from this review $[7,8]$.

CRF has shown capacity for alleviating pain in both episodic and chronic cluster headache. However, some evidence suggests the chronic form may be more difficult to treat. Filippini-De Moor et al. reported that $50 \%$ and $28 \%$ of patients, primarily with episodic cluster headache (17/19), experienced complete relief and no improvement, respectively, at 12 months post-procedure, which reduced to $28 \%$ and $37 \%$ over longer-term follow-up (9-64 months) [49]. In patients with chronic cluster headache, Narouze et al. reported that $20 \%$ and $20 \%$ of patients experienced complete relief and no improvement, respectively, at 18 months postprocedure [50]. The remainder of patients in these studies reported partial relief $[49,50]$. Comparisons between the studies performed by Filippini-De Moor et al. and Narouze et al. are problematic given the differences in follow-up. Sanders et al. offer a comparison between chronic and episodic cluster headache treated with CRF. However, the number of patients in the group with the episodic form was significantly greater ( $n=56$ vs. $n=10)$ [51]. Complete, partial, and no pain relief was reported in $61 \%, 25 \%$, and $14 \%$ of patients treated for the episodic form through $29.1 \pm 10.6$ months of post-procedure follow-up compared to 30\%, $30 \%$, and $40 \%$ of patients treated for the chronic form through $24.0 \pm 9.7$ months of post-procedure follow-up [51].

Salgado-López et al. reported similar efficacy between PRF and CRF when used to alleviate pain in chronic cluster headache, with $13.5 \%$ and $29.7 \%$ of patients reporting complete relief and no improvement, respectively, over a longterm follow up period with a mean of 68.1 (15-148) months, and the remaining patients reporting partial or transient relief (5.21 vs. 4.69 months in the PRF group) [52]. No statistically significant differences were found between the PRF and CRF groups for these metrics [52]. Fang et al. also reported significant reduction of symptoms in $12 / 16$ patients with primarily the episodic form (13/16) using PRF [53].

Additional studies have applied PRF and CRF more broadly to headache and facial pain syndromes such as neuralgias, neuropathies, migraine headaches, and atypical facial pain. Furthermore, case reports have noted long-term success in alleviating pain in post-traumatic headache and hemicrania continua [54, 55]. Using PRF, Bayer et al. reported that $21 \%$ and $14 \%$ of patients had complete pain relief and no improvement, respectively, with a range of follow-up between 4 and 52 months post-procedure [56]. This was similar to results reported by Akbas et al. at 3 months post-procedure (35\% and 23\%) [57]. The remainder and largest portion of patients in these studies reported partial relief (65\% and $42 \%$, respectively) [56, 57]. Using CRF, Oomen et al. reported that $60 \%$ of patients experienced $\geq 90 \%$ VAS reduction at 3 months post-procedure, with the remaining patients experiencing no or temporary relief [58]. In summary, RF treatment of sphenopalatine ganglion shows promise in treating headache and facial pain. Chronic cluster headache may be more difficult to treat than the episodic form, though successful outcomes were achieved in both. PRF and CRF also showed comparable long-term results.

Abdominal Pain Abdominal pain can be propagated through thoracic splanchnic nerves and their destination, the celiac plexus. Pain due to pancreatic and other abdominal cancers, chronic pancreatitis, and other abdominal pain of various origins were explored as candidates for $\mathrm{RF}$ in the studies included in this review. Initial management typically involves the World Health Organization (WHO) stepladder for medication escalation progressing from 
non-opioid analgesics and NSAIDs to mild opioids to strong opioids [5]. However, 20\% of patients remain refractory to treatment [5], and there is significant concern surrounding chronic use of opioids. Additional interventions such as nerve blocks, neurolysis, cordotomy, and infusion therapy can be essential in these patients [4, 5]. In cases where underlying abnormalities cannot be treated, chronic pancreatitis and other forms of abdominal pain can benefit from the same or similar therapies as pain due to abdominal cancer [73].

CRF has shown promise for alleviating abdominal pain of various causes, and evidence suggests it may have longer effects than chemical neurolysis. Raj et al. reported some of the earliest results on this topic [64], where 55-70\% of patients reported $>50 \%$ VAS reduction and $40 \%$ reported $>75 \%$ VAS reduction after receiving CRF at the T12 or T11 level over a 6-month follow-up period [64]. Focusing on pain due to various forms of abdominal cancer in a randomized controlled study, Amr et al. recommended the use of CRF at the T10 and T11 levels in place of chemical neurolysis at the T11 level [65]. Significant reductions in mean VAS score, global perceived effect satisfaction scores (GPES), and opioid consumption compared to baseline through 12 weeks of follow-up were reported only in the CRF group [65]. Quality of life (QoL) was also significantly better in the CRF group for the majority of follow-up [65]. In a similar patient population, Zhang et al. applied CRF using an endovascular approach to denervate the area of the abdominal aorta near the origin of the celiac artery [66]. The authors reported significant reductions in VAS scores and opioid usage through 12 weeks of follow-up, as well as QoL improvement over 8 weeks [66]. Given the diffuse nature of the pattern of innervation following the splanchnic nerves and celiac plexus, widespread application to various types of abdominal pain may be possible. Furthermore, case reports have demonstrated promise for long-term pain relief in both loin pain hematuria syndrome $[67,68]$ and autosomal dominant polycystic kidney disease [69].

In pancreatic cancer in particular, results using CRF and PRF were in agreement with the aforementioned studies on the use of RF in abdominal pain. Papadopoulos et al. applied PRF to splanchnic nerves at the T11 and T12 levels and reported significant improvement in mean NRS score, QoL, and opioid consumption through 5 months of follow-up post-procedure [69]. Beyond 5 months, natural progression of the disease appeared to influence these metrics [69]. Additionally, Bang et al. reported superiority of CRF compared to chemical neurolysis applied to the celiac ganglion during endoscopy as measured by pain relief (VAS, PAN26, C30, and BPI) and QoL (PAN26 and C30) through 3 weeks of post-procedure follow-up in a randomized controlled trial [71]. Moreover, three patients crossed over from the chemical neurolysis group to the CRF group after insufficient pain relief [71].

CRF has also been successfully applied in the setting of chronic pancreatitis. Garcea et al. applied CRF to splanchnic nerves at the T12 level, and patients reported a significant reduction in mean VAS scores, opiate use, acute admissions for pain, anxiety levels, daily activity, overall mood and general perception of health post-procedure over an 18 (12-24)month follow-up period [72]. Similarly, Verhaegh et al. applied CRF to splanchnic nerves at the T11 and T12 levels, and found that 78\% of patients reported $>50 \%$ reduction in VAS scores, in addition to long-term pain-free periods (45 weeks), significant decreases in mean NRS scores, and reduced need for analgesics [73]. In conclusion, RF treatment applied to the splanchnic nerves or the celiac plexus shows promise for relieving many different types of abdominal pain. In particular, CRF had better outcomes than chemical neurolysis in patients with abdominal cancer pain in two randomized controlled studies $[65,71]$.

Other Pain Conditions RF treatment has been applied to many different sympathetic sites for a wide array of pain conditions. Some additional studies are also worth mentioning that did not fall within the aforementioned types of pain. Forouzanfar et al. reported poorer results in patients undergoing CRF of the stellate ganglion for various types of head, face, neck, and upper extremity pain compared to 
aforementioned studies focusing on CRPS with a similar procedure, with $40.7 \%, 54.7 \%$, and $4.7 \%$ of patients experiencing $>50 \%$ improvement, no change, and worsening of VAS scores after the procedure, respectively [76]. Abbas et al. also used RF of the stellate ganglion, but instead focused specifically on patients with post-mastectomy neuropathic pain syndrome in a randomized controlled trial [77]. Better outcomes (VAS scores, functional improvement, and rescue analgesia) relative to baseline were reported in patients receiving CRF compared to PRF through the majority of the 24-week follow-up period [77]. Shaaban et al. similarly used PRF of the stellate ganglion to treat a few different neuropathic pain syndromes (post-mastectomy neuropathic pain syndrome, CRPS, and phantom pain), but compared fluoroscopic image guidance to ultrasound guidance in a randomized controlled trial [78]. Similar significant reductions relative to baseline in VAS as well as morphine and pregabalin consumption were seen in both groups after 3 months [78]. Additionally, Ding et al. compared the combined use of chemical neurolysis via anhydrous ethanol and CRF to these treatments alone applied to the lumbar sympathetic ganglia at the L2 and L3 vertebral levels for lower extremity painful diabetic peripheral neuropathy in a randomized controlled trial [79]. The greatest reduction in VAS was seen when the treatments were combined, though CRF outperformed chemical neurolysis over 1 year of follow-up [79]. Case reports and series have also shown long-term benefit in patients with pain stemming from vascular issues (i.e. ischemia and paraneoplastic Raynaud's syndrome) [80-82] and primary erythromelalgia [83].

\section{Complications}

As with any interventional procedure, complications are of major concern. Some of the most serious claims resulting from ablative (i.e. chemical or thermal) procedures for pain management are nerve injury, pneumothorax, and even brain damage or death [8]. Many of these serious complications can be avoided by proper patient selection and provider skill and knowledge to perform interventional RF techniques [8]. Furthermore, thorough knowledge of anatomy and proper utilization of image guidance (fluoroscopy, ultrasound, and computed tomography [CT]) can help interventionalists avoid damaging important neurovascular and organ structures surrounding many of the target SNS sites. The vast majority of studies included in this review utilized fluoroscopic guidance. However, ultrasound [35, 77, 78] and CT [33] proved useful in navigating anatomic structures surrounding the stellate ganglion. Furthermore, endoscopic ultrasound [71, 74] and endovascular [66] approaches are useful for reaching the celiac plexus, as opposed to percutaneous methods used at other SNS sites.

In the studies included in this review, reported complications were typically minor and transient. Complications were also more frequent in CRF procedures than in PRF procedures. Complications can be broken down into puncture-related (non-neuropathic) pain, infection, bleeding, neurogenic complications, and systemic complications. Puncture-related pain was localized to the injection site and resolved relatively quickly $[29,65,78,81]$. A short-lived infection was only reported in one study, which investigated RF of the ganglion impar [40]. Bleeding was reported only at superiorly located SNS sites (stellate ganglion and sphenopalatine ganglion) and included either a local bleed (epistaxis) [51] or hematoma formation at the puncture site $[34,78]$, in the cheek [51] or in the prevertebral region [33]. Neurogenic complications included neuropathic pain (post-sympathectomy neuralgia [28], paresthesia [29, 50], and regional pain $[65,84])$ and non-pain-related complications (hypoesthesia [51, 73], Horner's syndrome [33], ptosis [77], and off-target nerve lesions [51] using CRF and voice hoarseness using PRF [78]). Of note, Horner's syndrome [33] and ptosis [77] occurred exclusively after targeting the stellate ganglion. Systemic complications included vasovagal collapse after applying CRF to the stellate ganglion [34] as well as hypotension, abdominal colic, and diarrhea after applying CRF to splanchnic nerves $[65,72]$. Temporary hypotension also occurred when CRF was 
applied to lumbar sympathetic ganglia in combination with chemical neurolysis [79]. Overall, $\mathrm{RF}$ is a relatively safe procedure compared to other neurolytic techniques, and complications can be avoided through precise anatomic localization [18]. However, RF should be employed with great caution given the range of possible complications. PRF further enhances the safety of RF by preventing destructive buildup of heat and should, therefore, be recommended in place of CRF if efficacy is comparable $[18,19]$.

\section{CONCLUSIONS}

The SNS is implicated in numerous pain conditions including CRPS, pain in the perineal region, headache and facial pain, abdominal pain, and others. Interventional RF treatment holds promise as an effective strategy to relieve patients of debilitating pain who are otherwise refractory to more conservative medical management. However, limited high-quality data exist to support its use in the SNS. Evidence is primarily found in retrospective studies and case series and reports. Only seven randomized controlled studies of various size were found in this literature search [29, 40, 65, 71, 77-79]. This led to significant variability in the reported outcomes including how pain was assessed, how success of the procedure was determined, and how follow-up was conducted postprocedure.

Given current data, candidates for RF procedures should be carefully selected. Qualifying factors such as type of pain, having pain refractory to conservative medical management, and demonstrated temporary relief from a diagnostic block at the intended target site among others can help determine if patients are likely to benefit from RF intervention [10-12]. Despite careful selection, results varied to some extent between studies, which may be due in large part to differences in how outcomes were reported. In the studies included in this review, the proportion of patients that did not experience an improvement in pain after an RF procedure varied from as low as 5 or $10 \%$ $[34,35,38]$ to as high as $40 \%$ [51] or $58 \%$ [76], but generally this proportion fell within the range of $10-30 \%$.

Both CRF and PRF show promise to be effective procedures for relieving SMP, but with some risk of complication. Fortunately, many of the complications are minor and temporary. Possible complications should be weighed against potential benefit. After careful patient selection, thorough understanding of both the anatomy of the target site and optimal RF procedure parameters can facilitate success and avoid complications. In the studies included in this review, exact parameters of RF were variable. Electrode sizes ranged from 20 to $22 \mathrm{G}$ with 4-15 $\mathrm{mm}$ active tips. CRF and PRF applications also varied in temperature, time, and number. $\mathrm{CRF}$ temperatures were in the range of $60-90^{\circ} \mathrm{C}$ and PRF was delivered at temperatures less than $42{ }^{\circ} \mathrm{C}$. CRF application time ranged from 60 to $90 \mathrm{~s}$ whereas PRF varied from 2 to 7 min with a variable number of applications. Future studies are needed to further refine the RF technique to ensure optimal application of procedure parameters, to make further comparisons between RF treatment and other commonly used interventional techniques (e.g., chemical neurolysis, anesthetic block, and spinal cord stimulation), and to make comparisons between CRF and PRF prior to incorporating either of the $\mathrm{RF}$ modalities into common practice.

\section{ACKNOWLEDGEMENTS}

Funding. Nicholas Zacharias received funding from the University of Wisconsin-Madison School of Medicine and Public Health (Madison, WI, USA) Shapiro Summer Research Program in support of his work on this review. No Rapid Service Fee was received by the journal for the publication of this article.

Authorship. All named authors meet the International Committee of Medical Journal Editors (ICMJE) criteria for authorship for this article, take responsibility for the integrity of the work as a whole, and have given their approval for this version to be published. 
Disclosures. All authors (Nicholas A. Zacharias, Jay Karri, Carol Garcia, Laura K. Lachman and Alaa Abd-Elsayed) declare that they have no conflict of interest related to this work. Nicholas Zacharias received funding from the University of Wisconsin-Madison School of Medicine and Public Health (Madison, WI, USA) Shapiro Summer Research Program. Dr. Alaa Abd-Elsayed is a consultant for Medtronic and Avanos and a member of the journal's Editorial Board.

Compliance with Ethics Guidelines. All data presented in this review are from previously published studies, and the review does not contain any studies performed by the authors of this article.

Data Availability. All data generated or analyzed during this study are included in this published article.

Open Access. This article is licensed under a Creative Commons Attribution-NonCommercial 4.0 International License, which permits any non-commercial use, sharing, adaptation, distribution and reproduction in any medium or format, as long as you give appropriate credit to the original author(s) and the source, provide a link to the Creative Commons licence, and indicate if changes were made. The images or other third party material in this article are included in the article's Creative Commons licence, unless indicated otherwise in a credit line to the material. If material is not included in the article's Creative Commons licence and your intended use is not permitted by statutory regulation or exceeds the permitted use, you will need to obtain permission directly from the copyright holder. To view a copy of this licence, visit http:// creativecommons.org/licenses/by-nc/4.0/.

\section{REFERENCES}

1. Jänig W, Levine J. Autonomic, endocrine, and immune interactions in acute and chronic pain. In: McMahon S, Koltzenburg M, Tracey I, Turk D, editors. Wall \& Melzack's textbook of pain. 6th ed. Philadelphia: Elsevier; 2013. p. 198-210.

2. Binder A, Baron R. Complex regional pain syndromes. In: McMahon S, Koltzenburg M, Tracey I, Turk D, editors. Wall \& Melzack's textbook of pain. 6th ed. Philadelphia: Elsevier; 2013. p. 961-77.

3. van Kleef $M$, Lataster A, Narouze S, Mekhail N, Geurts JW, van Zundert J. Evidence-based interventional pain medicine according to clinical diagnoses. 2. Cluster headache. Pain Pract. 2009;9(6):435-42. https://doi.org/10.1111/j.15332500.2009.00331.x.

4. Filippiadis D, Tutton S, Kelekis A. Pain management: The rising role of interventional oncology. Diagn Interv Imaging. 2017;98(9):627-34. https:// doi.org/10.1016/j.diii.2017.06.015.

5. Careskey H, Narang S. Interventional anesthetic methods for pain in hematology/oncology patients. Hematol Oncol Clin North Am. 2018;32(3):433-45. https://doi.org/10.1016/j.hoc.2018.01.007.

6. Wesselmann U, Burnett AL, Heinberg LJ. The urogenital and rectal pain syndromes. Pain. 1997;73(3):269-94. https://doi.org/10.1016/s03043959(97)00076-6.

7. Day M. Sympathetic blocks: the evidence. Pain Pract. 2008;8(2):98-109. https://doi.org/10.1111/j. 1533-2500.2008.00177.x.

8. Carlson J, Hogan P. Complications related to radiofrequency procedures for the treatment of chronic pain. In: Ranson M, Pope J, Deer T, editors. Reducing risks and complications of interventional pain procedures. Philadelphia: Elsevier; 2012. p. $55-69$.

9. Chen SS, Zhang JM. Progress in sympathetically mediated pathological pain. J Anesth Perioper Med. 2015;2(4):216-25. https://doi.org/10.24015/JAPM. 2015.0029 .

10. Waldman S. Lumbar sympathetic Ganglion Block: radiofrequency lesioning. In: Atlas of interventional pain management, 5th ed. Chap 99, Philadelphia: Elsevier; 2021. p. 542-5.

11. Waldman S. Sphenopalatine Ganglion Block: radiofrequency lesioning. In: Atlas of interventional pain management, 5th ed. Char 6, Philadelphia: Elsevier; 2021. p. 24-6.

12. Waldman S. Stellate Ganglion Block: radiofrequency lesioning. Atlas of interventional pain management. 5th edn. Philadelphia: Elsevier; 2021. pp. 172-6. 
13. Ashkenazi A, Schwedt T. Cluster headache-acute and prophylactic therapy. Headache. 2011;51(2): 272-86. https://doi.org/10.1111/j.1526-4610.2010. 01830.x.

14. Elkhashab $\mathrm{Y}, \mathrm{Ng} \mathrm{A}$. A review of current treatment options for coccygodynia. Curr Pain Headache Rep. 2018;22(4):28. https://doi.org/10.1007/s11916-0180683-7.

15. Patijn J, Janssen M, Hayek S, Mekhail N, Van Zundert J, van Kleef M. 14. Coccygodynia. Pain Pract. 2010;10(6):554-9. https://doi.org/10.1111/j.15332500.2010.00404.x.

16. Malik K. Pulsed radiofrequency, water-cooled radiofrequency, and cryoneurolysis. In: Benzon HT, Raja S, Liu SS, Fishman S, Cohen SP, editors. Essentials of pain medicine. 4 th ed. Philadelphia: Elseiver; 2018. p. 619-26.

17. Williams K, Guarino A, Raja S. Complex Regional Pain Syndrome. In: Benzon HT, Raja S, Liu SS, Fishman S, Cohen SP, editors. Essentials of pain medicine. 4th ed. Philadelphia: Elseiver; 2018. p. 223-32.

18. Rosenthal R. Radiofrequency Lesioning. In: Waldman S, editor. Pain management. 2nd ed. Philadelphia: Elsevier; 2011. p. 1331-60.

19. van Eerd M, van Kleef M, Van Zundert J. Radiofrequency Treatment. In: Benzon H, Rathmell J, Wu C, Turk D, Argoff C, Hurley R, editors. Practical management of pain. 5th ed. Philadelphia: Elsevier; 2014. p. 846-65.

20. Albayrak I, Apiliogullari S, Onal O, Gungor C, Saltali A, Levendoglu F. Pulsed radiofrequency applied to the dorsal root ganglia for treatment of poststroke complex regional pain syndrome: a case series. J Clin Anesth. 2016;33:192-7. https://doi. org/10.1016/j.jclinane.2016.03.059.

21. Apiliogullari S, Aydin BK, Onal O, Kirac Y, Celik JB. Pulsed radiofrequency of dorsal root ganglia for the treatment of complex regional pain syndrome in an adolescent with poliomyelitis sequel: a case report. Pain Med. 2015;16(7):1369-72. https://doi.org/10. 1111/pme.12710.

22. Kim $\mathrm{HS}, \mathrm{Wu} \mathrm{PH}$, Jang IT. Lumbar degenerative disease part 1: anatomy and pathophysiology of intervertebral discogenic pain and radiofrequency ablation of basivertebral and sinuvertebral nerve treatment for chronic discogenic back pain: a prospective case series and review of literature. Int J Mol Sci. 2020. https://doi.org/10.3390/ ijms21041483.
23. Peripheral GI, Pathways A. In: Mai J, editor. The human nervous system. 3rd ed. Philedelphia: Elsevier; 2012. p. 141-85.

24. Waldman S. Thoracic sympathetic Ganglion block. Atlas of interventional pain management, 5th edn. Philadelphia: Elsevier; 2021. pp. 383-7.

25. Waldman S. Splanchnic nerve block: classic twoneedle technique. Atlas of interventional pain management, 5th edn. Philadelphia: Elsevier; 2021. pp. 429-35.

26. Waldman S. Ganglion of Walther (Impar) block: transcoccygeal technique. Atlas of interventional pain management, 5th edn. Philadelphia: Elsevier; 2021. pp. 753-6.

27. Liberati A, Altman DG, Tetzlaff J, et al. The PRISMA statement for reporting systematic reviews and meta-analyses of studies that evaluate health care interventions: explanation and elaboration. PLoS Med. 2009. https://doi.org/10.1371/journal.pmed. 1000100 .

28. Haynsworth RF Jr, Noe CE. Percutaneous lumbar sympathectomy: a comparison of radiofrequency denervation versus phenol neurolysis. Anesthesiology. 1991;74(3):459-63.

29. Manjunath PS, Jayalakshmi TS, Dureja GP, Prevost AT. Management of lower limb complex regional pain syndrome type 1: an evaluation of percutaneous radiofrequency thermal lumbar sympathectomy versus phenol lumbar sympathetic neurolysis-a pilot study. Anesth Analg. 2008;106(2):647-9. https://doi.org/10.1213/01.ane. 0000298285.39480 .28 (table of contents).

30. Akkoc Y, Uyar M, Oncu J, Ozcan Z, Durmaz B. Complex regional pain syndrome in a patient with spinal cord injury: management with pulsed radiofrequency lumbar sympatholysis. Spinal Cord. 2008;46(1):82-4. https://doi.org/10.1038/sj.sc. 3102074 .

31. Djuric V. Pulsed radiofrequency treatment of complex regional pain syndrome: a case series. Pain Res Manag. 2014;19(4):186-90. https://doi.org/10. $1155 / 2014 / 835083$.

32. Singh Rana SP, Abraham M, Gupta V, Biswas S, Marda M. Stellate ganglion pulsed radiofrequency ablation for stretch induced complex regional pain syndrome type II. Saudi J Anaesth. 2015;4:470-3.

33. Kastler A, Aubry S, Sailley N, et al. CT-guided stellate ganglion blockade vs. radiofrequency neurolysis in the management of refractory type I complex regional pain syndrome of the upper limb. Eur Radiol. 2013;23(5):1316-22. https://doi.org/10. 1007/s00330-012-2704-y. 
34. Geurts JWM. Percutaneous radiofrequency lesion of the stellate ganglion in the treatment of pain in upper extremity reflex sympathetic dystrophy. Pain Clin. 1993;6(1):17-25.

35. Kim ED, Yoo WJ, Kim YN, Park HJ. Ultrasoundguided pulsed radiofrequency treatment of the cervical sympathetic chain for complex regional pain syndrome: a retrospective observational study. Medicine (Baltimore). 2017;96(1):e5856. https:// doi.org/10.1097/md.0000000000005856.

36. Park J, Lee YJ, Kim ED. Clinical effects of pulsed radiofrequency to the thoracic sympathetic ganglion versus the cervical sympathetic chain in patients with upper-extremity complex regional pain syndrome: a retrospective analysis. Medicine (Baltimore). 2019;98(5):e14282. https://doi.org/10. 1097/md.0000000000014282.

37. Reig E, Abejón D, del Pozo C, Insausti J, Contreras R. Thermocoagulation of the ganglion impar or ganglion of Walther: description of a modified approach. Preliminary results in chronic, nononcological pain. Pain Pract. 2005;5(2):103-10. https://doi.org/10.1111/j.1533-2500.2005.05206.x.

38. Demircay E, Kabatas S, Cansever T, Yilmaz C, Tuncay C, Altinors N. Radiofrequency thermocoagulation of ganglion impar in the management of coccydynia: preliminary results. Turk Neurosurg. 2010;20(3):328-33. https://doi.org/10.5137/10195149.jtn.2852-09.0.

39. Kircelli A, Demirçay E, Özel Ö, et al. Radiofrequency thermocoagulation of the ganglion impar for coccydynia management: long-term effects. Pain Pract. 2019;19(1):9-15. https://doi.org/10.1111/papr. 12698.

40. Usmani H, Dureja GP, Andleeb R, Tauheed N, Asif $N$. Conventional radiofrequency thermocoagulation vs pulsed radiofrequency neuromodulation of ganglion impar in chronic perineal pain of nononcological origin. Pain Med. 2018;19(12): 2348-56. https://doi.org/10.1093/pm/pnx244.

41. Atim A, Ergin A, Bilgiç S, Deniz S, Kurt E. Pulsed radiofrequency in the treatment of coccygodynia. Agri. 2011;23(1):1-6. https://doi.org/10.5505/agri. 2011.59002 .

42. Gopal H, Mc CC. Coccygodynia treated by pulsed radio frequency treatment to the Ganglion of Impar: a case series. J Back Musculoskelet Rehabil. 2014;27(3):349-54. https://doi.org/10.3233/bmr140454 .

43. Karaman H, Tüfek A, Kavak GO, Yildirim ZB, Celik F. Would pulsed radiofrequency applied to different anatomical regions have effective results for chronic pain treatment? J Pak Med Assoc. 2011;61(9):879-85.

44. Sir E, Eksert S. Comparison of block and pulsed radiofrequency of the ganglion impar in coccygodynia. Turk J Med Sci. 2019;49(5):1555-9. https:// doi.org/10.3906/sag-1906-51.

45. Gürses E. Impar ganglion radiofrequency application in successful management of oncologic perineal pain. J Pak Med Assoc. 2014;64(6):697-9.

46. Keun Sook K, Hyun Hak K, Sung Mi H, So Young L, Soon Yong H, Keun MS. Stereotactic neurotomy of the Ganglion impar through the sacrococcygeal junction in cancer-related perianal pain-a case report. Korean J Pain. 2005;18(2):263-6.

47. Kim JH, Kim E, Kim BI. Pulsed radiofrequency treatment of the superior hypogastric plexus in an interstitial cystitis patient with chronic pain and symptoms refractory to oral and intravesical medications and bladder hydrodistension: a case report. Medicine (Baltimore). 2016;95(49):e5549. https:// doi.org/10.1097/md.0000000000005549.

48. Usta B, Gozdemir M, Sert H, Muslu B, Demircioglu RI. Fluoroscopically guided ganglion impar block by pulsed radiofrequency for relieving coccydynia. J Pain Symptom Manage. 2010;6:e1-2.

49. Filippini-De MG. Retrospective analysis of radiofrequency lesions of the sphenopalatine ganglion in the treatment of 19 cluster headache patients. Pain Clin. 1999;11(4):285-91.

50. Narouze S, Kapural L, Casanova J, Mekhail N. Sphenopalatine ganglion radiofrequency ablation for the management of chronic cluster headache. Headache. 2009;49(4):571-7. https://doi.org/10. 1111/j.1526-4610.2008.01226.x.

51. Sanders M, Zuurmond WW. Efficacy of sphenopalatine ganglion blockade in 66 patients suffering from cluster headache: a 12- to 70-month follow-up evaluation. J Neurosurg. 1997;87(6):876-80. https://doi.org/10.3171/jns.1997.87.6.0876.

52. Salgado-López L, de Quintana-Schmidt C, Belvis Nieto R, et al. Efficacy of sphenopalatine Ganglion radiofrequency in refractory chronic cluster headache. World Neurosurg. 2019;122:e262-9. https:// doi.org/10.1016/j.wneu.2018.10.007.

53. Fang L, Jingjing L, Ying S, Lan M, Tao W, Nan J. Computerized tomography-guided sphenopalatine ganglion pulsed radiofrequency treatment in 16 patients with refractory cluster headaches: twelveto 30-month follow-up evaluations. Cephalalgia. 2016;36(2):106-12. https://doi.org/10.1177/ 0333102415580113. 
54. Shah RV, Racz GB. Long-term relief of posttraumatic headache by sphenopalatine ganglion pulsed radiofrequency lesioning: a case report. Arch Phys Med Rehabil. 2004;85(6):1013-6. https://doi.org/ 10.1016/j.apmr.2003.07.017.

55. Beams JL, Kline MT, Rozen TD. Treatment of hemicrania continua with radiofrequency ablation and long-term follow-up. Cephalalgia. 2015;35(13): 1208-13. 0333102415575726.

56. Bayer E, Racz GB, Miles D, Heavner J. Sphenopalatine ganglion pulsed radiofrequency treatment in 30 patients suffering from chronic face and head pain. Pain Pract. 2005;5(3):223-7. https://doi.org/ 10.1111/j.1533-2500.2005.05314.x.

57. Akbas M, Gunduz E, Sanli S, Yegin A. Sphenopalatine ganglion pulsed radiofrequency treatment in patients suffering from chronic face and head pain. Braz J Anesthesiol. 2016;66(1):50-4. https://doi.org/ 10.1016/j.bjane.2014.06.001.

58. Oomen KP, van Wijck AJ, Hordijk GJ, de Ru JA. Effects of radiofrequency thermocoagulation of the sphenopalatine ganglion on headache and facial pain: correlation with diagnosis. J Orofac Pain. 2012;26(1):59-64.

59. Carcamo CR. Pulsed radiofrequency of superior cervical sympathetic ganglion for treatment of refractory migraine. Pain Med. 2017;8:1598-600.

60. Loomba V, Upadhyay A, Kaveeshvar H. Radiofrequency ablation of the sphenopalatine Ganglion using cone beam computed tomography for intractable cluster headache. Pain Phys. 2016;19(7): E1093-6.

61. Bendersky DC, Hem SM, Yampolsky CG. Unsuccessful pulsed radiofrequency of the sphenopalatine ganglion in patients with chronic cluster headache and subsequent successful thermocoagulation. Pain Pract. 2015;15(5):E40-5. https://doi.org/10.1111/ papr.12288.

62. Chua NH, Vissers KC, Wilder-Smith OH. Quantitative sensory testing may predict response to sphenopalatine ganglion pulsed radiofrequency treatment in cluster headaches: a case series. Pain Pract. 2011;11(5):439-45. https://doi.org/10.1111/j. 1533-2500.2010.00445.x.

63. Salar G, Ori C, Iob I, Fiore D. Percutaneous thermocoagulation for sphenopalatine ganglion neuralgia. Acta Neurochir (Wien). 1987;84(1-2):24-8. https://doi.org/10.1007/bf01456346.

64. Raj PP, Sahinler B, Lowe M. Radiofrequency lesioning of splanchnic nerves. Pain Pract.
2002;2(3):241-7. https://doi.org/10.1046/j.15332500.2002.02030.x.

65. Amr SA, Reyad RM, Othman AH, et al. Comparison between radiofrequency ablation and chemical neurolysis of thoracic splanchnic nerves for the management of abdominal cancer pain, randomized trial. Eur J Pain. 2018;22(10):1782-90. https:// doi.org/10.1002/ejp.1274.

66. Zhang Q, Guo JH, Zhu HD, et al. Endovascular denervation: a new approach for cancer pain relief? J Vasc Interv Radiol. 2018;29(12):1639-44. https:// doi.org/10.1016/j.jvir.2018.08.008.

67. Moeschler SM, Hoelzer BC, Eldrige JS. A patient with loin hematuria syndrome and chronic flank pain treated with pulsed radiofrequency of the splanchnic nerves. Clin J Pain. 2013;29(11):e26-9. https://doi.org/10.1097/AJP.0b013e31828c8922.

68. Gambaro G, Fulignati P, Spinelli A, Rovella V, Di Daniele N. Percutaneous renal sympathetic nerve ablation for loin pain haematuria syndrome. Nephrol Dial Transpl. 2013;28(9):2393-5. https:// doi.org/10.1093/ndt/gft059.

69. Casteleijn NF, de Jager RL, Neeleman MP, Blankestijn PJ, Gansevoort RT. Chronic kidney pain in autosomal dominant polycystic kidney disease: a case report of successful treatment by catheterbased renal denervation. Am J Kidney Dis. 2014;63(6):1019-21. https://doi.org/10.1053/j.ajkd. 2013.12.011.

70. Papadopoulos D, Kostopanagiotou G, Batistaki C. Bilateral thoracic splanchnic nerve radiofrequency thermocoagulation for the management of endstage pancreatic abdominal cancer pain. Pain Phys. 2013;16(2):125-33.

71. Bang JY, Sutton B, Hawes RH, Varadarajulu S. EUSguided celiac ganglion radiofrequency ablation versus celiac plexus neurolysis for palliation of pain in pancreatic cancer: a randomized controlled trial (with videos). Gastrointest Endosc. 2019;89(1):5866.e3. https://doi.org/10.1016/j.gie.2018.08.005.

72. Garcea G, Thomasset S, Berry DP, Tordoff S. Percutaneous splanchnic nerve radiofrequency ablation for chronic abdominal pain. ANZ J Surg. 2005;75(8):640-4. https://doi.org/10.1111/j.14452197.2005.03486.x.

73. Verhaegh BP, van Kleef M, Geurts JW, et al. Percutaneous radiofrequency ablation of the splanchnic nerves in patients with chronic pancreatitis: results of single and repeated procedures in 11 patients. Pain Pract. 2013;13(8):621-6. https://doi.org/10. 1111/papr.12030. 
74. Jin ZD, Wang L, Li Z. Endoscopic ultrasound-guided celiac ganglion radiofrequency ablation for pain control in pancreatic carcinoma. Dig Endosc. 2015;27(1):163-4. https://doi.org/10.1111/den. 12398.

75. Brennan L, Fitzgerald J, McCrory C. The use of pulsed radiofrequency treatment for chronic benign pancreatitis pain. Pain Pract. 2009;9(2): 135-40. https://doi.org/10.1111/j.1533-2500.2008. 00254.x.

76. Forouzanfar T, van Kleef M, Weber WE. Radiofrequency lesions of the stellate ganglion in chronic pain syndromes: retrospective analysis of clinical efficacy in 86 patients. Clin J Pain. 2000;16(2): 164-8. 200006000-00010.

77. Abbas DN, Reyad RM. Thermal versus super voltage pulsed radiofrequency of stellate Ganglion in postmastectomy neuropathic pain syndrome: a prospective randomized trial. Pain Phys. 2018;21(4):351-62.

78. Shaaban MH, Reyad RM, Ghobrial HZ, Hashem RH. Ultrasound guided versus fluroscopic guided pulsed radiofrequency therapy of the stellate ganglion in neuropathic pain: a prospective controlled comparative study. Egypt J Radiol Nucl Med. 2018;49(1):71-5. https://doi.org/10.1016/j.ejrnm. 2017.06.008.

79. Ding Y, Yao P, Li H, Zhao R, Zhao G. Evaluation of combined radiofrequency and chemical blockade of multi-segmental lumbar sympathetic ganglia in painful diabetic peripheral neuropathy. J Pain Res. 2018;11:1375-82. https://doi.org/10.2147/JPR. S175514.
80. Sekhri NK, Parikh S, Foo RM. Radiofrequency ablation of the Stellate Ganglion for management of acute digital ischemia: a case report. A A Pract. 2018;11(7):189-92. https://doi.org/10.1213/xaa. 0000000000000869.

81. Gabrhelik T, Stehlik D, Adamus M, Zalesak B, Michalek P. Radiofrequency upper thoracic sympathectomy in the treatment of critical upper limb ischemia-a case series. Biomed Pap Med Fac Univ Palacky Olomouc Czech Repub. 2013;157(2):202-8. https://doi.org/10.5507/bp.2011.055.

82. Gofeld M, Faclier G. Bilateral pain relief after unilateral thoracic percutaneous sympathectomy. Can J Anaesth. 2006;53(3):258-62. https://doi.org/10. 1007/bf03022212.

83. Lee JY, Sim WS, Kang RA, Lee EK, Yang JY, Kim DY. Lumbar sympathetic pulsed radiofrequency treatment for primary erythromelalgia: a case report. Pediatr Dermatol. 2017;34(1):e47-50. https://doi. org/10.1111/pde.12985.

84. Rocco AG. Radiofrequency lumbar sympatholysis The evolution of a technique for managing sympathetically maintained pain. Reg Anesth. 1995;20(1):3-12.

85. Samuelsson H, Claes G, Drott C. Endoscopic electrocautery of the upper thoracic sympathetic chain: a safe and simple technique for treatment of sympathetically maintained pain. Eur J Surg Suppl. 1994;572:55-7.

86. Cornelissen P, van Kleef M, Mekhail N, Day M, van Zundert J. Evidence-based interventional pain medicine according to clinical diagnoses. 3. Persistent idiopathic facial pain. Pain Pract. 2009;9(6): 443-8. https://doi.org/10.1111/j.1533-2500.2009. 00332.x. 